\title{
Subcellular targeting and dynamic regulation of PTEN: implications for neuronal cells and neurological disorders
}

\author{
Patricia Kreis $^{1+}$, George Leondaritis ${ }^{1,2 t}$, Ivo Lieberam ${ }^{1}$ and Britta J. Eickholt ${ }^{1,2 *}$ \\ ${ }^{1}$ MRC Centre for Developmental Neurobiology, King's College London, London, UK \\ 2 Institute of Biochemistry, Charité - Universitätsmedizin Berlin, Berlin, Germany
}

\author{
Edited by: \\ Bryan Weston Luikart, Geisel School \\ of Medicine at Dartmouth, USA \\ Reviewed by: \\ Kirsten Harvey, University College \\ London, UK \\ Bernhard Lüscher, Pennsylvania \\ State University, USA \\ *Correspondence: \\ Britta J. Eickholt, Institute of \\ Biochemistry, Charité - \\ Universitätsmedizin Berlin, \\ Charitéplatz 1, D-10117 Berlin, \\ Germany \\ e-mail: britta.eickholt@charite.de \\ ${ }^{\dagger}$ These authors have contributed \\ equally to this work.
}

PTEN is a lipid and protein phosphatase that regulates a diverse range of cellular mechanisms. PTEN is mainly present in the cytosol and transiently associates with the plasma membrane to dephosphorylate PI(3,4,5)P3, thereby antagonizing the PI3-Kinase signaling pathway. Recently, PTEN has been shown to associate also with organelles such as the endoplasmic reticulum (ER), the mitochondria, or the nucleus, and to be secreted outside of the cell. In addition, PTEN dynamically localizes to specialized sub-cellular compartments such as the neuronal growth cone or dendritic spines. The diverse localizations of PTEN imply a tight temporal and spatial regulation, orchestrated by mechanisms such as posttranslational modifications, formation of distinct protein-protein interactions, or the activation/recruitment of PTEN downstream of external cues. The regulation of PTEN function is thus not only important at the enzymatic activity level, but is also associated to its spatial distribution. In this review we will summarize (i) recent findings that highlight mechanisms controlling PTEN movement and sub-cellular localization, and (ii) current understanding of how PTEN localization is achieved by mechanisms controlling posttranslational modification, by association with binding partners and by PTEN structural or activity requirements. Finally, we will discuss the possible roles of compartmentalized PTEN in developing and mature neurons in health and disease.

Keywords: PTEN phosphohydrolase, neuronal morphology, synaptic transmission, membranes, PI3K/AKT/mTOR

\section{INTRODUCTION}

Phosphatase and tensin homolog located on chromosome 10 (PTEN) was originally characterized as a tumor suppressor that can inhibit proliferation, migration, cell growth, and apoptosis in a number of different cells. Subsequently it became apparent that,

Abbreviations: ASD, Autism spectrum disorders; AMPAR, $\alpha$-Amino-3-hydroxy5-methyl-4-isoxazolepropionic acid receptor; BRRS, Bannayan-Riley-Ruvalcaba syndrome; cKO, conditional knockout; CNS, central nervous system; CS, Cowden syndrome; Drebrin, Developmentally regulated brain protein; DRG, dorsal root ganglia; FRET, Fluorescence resonance energy transfer; GAP, GTPase Activating Protein; GEF, Guanine nucleotide Exchange Factor; GFAP, glial fibrillary acidic protein; GPCR, G-protein coupled receptor; GSK3, glycogen synthase kinase; InsP3R, inositol 1,4,5-trisphosphate receptor; LDD, Lhermitte-Duclos disease; LTD, long-term depression; LTP, long-term potentiation; MAGs, myelin-associated glycoproteins; mTOR, mammalian target of rapamycin; MAM, mitochondriaassociated membrane; Nedd4, neural precursor cell-expressed developmentally downregulated gene 4; Ndfip1, Nedd4 family interacting protein-1; NEP, Neutral Endopeptidase; NGF, nerve growth factor; NHERF, $\mathrm{Na}(+) / \mathrm{H}(+)$ exchanger regulatory factor; NMDAR, N-methyl-D-aspartate receptor; NSE, neuron-specific enolase; PBM, PIP2-binding motif; PDGFR, Platelet-derived growth factor receptor; PDK1, phosphoinositide-dependent kinase 1; PDZ, post synaptic density protein (PSD95), Disc large tumor suppressor (Dlg1), and zonula occludens-1 protein (zo-1); PH, pleckstrin homology; PHLPP, PH domain and Leucine-rich repeat Protein Phosphatase; PHTS, PTEN hamartoma tumor syndromes; PI3,4P2, phosphatidylinositol 3,4-bisphosphate; PI3K, phosphoinositide 3 kinase; PIP2, phosphatidylinositol 4,5-bisphosphate; PIP3, phosphatidylinositol 3,4,5-trisphosphate; PNS, peripheral nervous system; PS, Proteus syndrome; PSD, post synaptic density; PSL, Proteus-like syndrome; PTEN, Phosphatase and tensin homolog located on chromosome 10; RHEB, Ras Homolog Enriched in Brain; SHIP, SH2-domain containing inositol 5-phosphatase; shRNA, short-hairpin RNA; TBI, traumatic brain injury; TSC, Tuberous Sclerosis Complex. in addition to its role as a tumor suppressor, PTEN has many roles in the central nervous system (CNS) during the different stages of brain development and in adulthood. PTEN is highly expressed in neurons (Lachyankar et al., 2000; Chadborn et al., 2006) and recent work indicates that de-regulation of PTEN affects important neuronal functions in the nervous system, which have been attributed to its role in controlling neurogenesis, neurite outgrowth, synaptogenesis, and synaptic plasticity (Van Diepen and Eickholt, 2008; Zhou and Parada, 2012). Human germline PTEN mutations or conditional deletions of PTEN in mice have provided insights into possible causes associated with neurological disorders such as macrocephaly, ataxia, seizures, mental retardation, and autism (Backman et al., 2001; Kwon et al., 2006; Van Diepen and Eickholt, 2008; Zhou and Parada, 2012). Also, inhibition of PTEN activity is currently seen as a persuasive target for increasing regenerative capacities of neurons affected in degenerative conditions, or following injury to the nervous system (Park et al., 2008).

\section{PTEN, A PHOSPHOINOSITIDE 3-PHOSPHATASE THAT REGULATES PI3K (PHOSPHOINOSITIDE 3 KINASE) SIGNALING}

PTEN functions predominately by directly antagonizing the activity of PI3K class I heterodimeric enzymes at the plasma membrane (Figure 1A). Class I PI3Ks are activated by a broad array of growth factors, components of the extracellular matrix, and Gprotein coupled receptor (GPCR) agonists (Hawkins et al., 2006; 


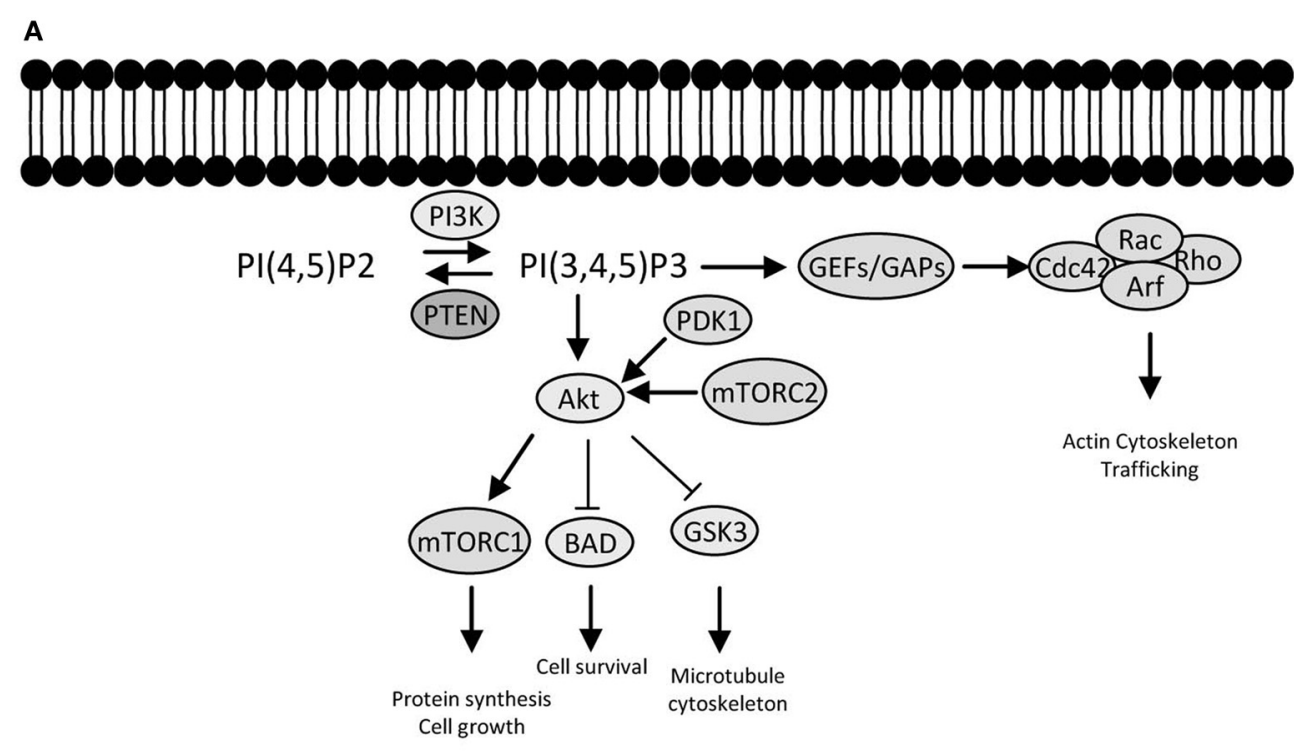

B

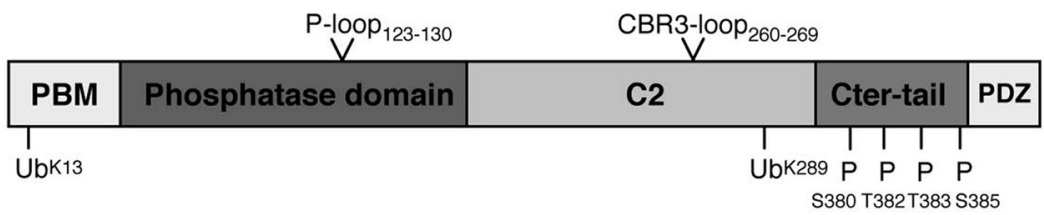

FIGURE 1 | PI3K signaling, PTEN, and downstream effector pathways. (A) One of the most prominent PIP3 effectors is the protein kinase Akt. Upon PI3K activation, Akt translocates from the cytosol to the membrane, where it binds PIP3 and is phosphorylated and activated by PDK1 (phosphoinositide-dependent kinase 1) and the rapamycin-insensitive complex containing mTOR (mammalian target of rapamycin), mTORC2. Akt is considered as a master regulator of cell growth and proliferation, as well as survival, by phosphorylating and regulating the activity of several proteins, which convey growth-factor-derived signals to cellular functions. For example, Akt phosphorylates and inactivates TSC2 (Tuberous Sclerosis Complex 2), which, in a complex with TSC1, is responsible for inhibition of RHEB (Ras Homolog Enriched in Brain). Thus, release of this inhibition results in activation of mTORC1 complex, which is important for promoting protein translation and accelerating cell growth in neurons. Its deregulation is associated with several neurodevelopmental disorders (Costa-Mattioli and Monteggia, 2013). Akt also phosphorylates and inactivates GSK3 (glycogen synthase kinase 3), a serine/threonine kinase that has been associated with a number of neuronal responses, particularly during neuronal development by regulating microtubule dynamics (Hur and Zhou, 2010). Besides Akt, PIP3 also provide a signal for membrane recruitment and activation of a number of small GTPase regulators, particularly GEFs (Guanine nucleotide Exchange Factors) and GAPs (GTPase Activating Proteins) of the Rho and Arf families of GTPases (Krugmann et al., 2002; Welch et al., 2002). In this manner PI3K, can regulate the activation state of Rho and Arf family GTPases, thereby influencing cytoskeletal and vesicular trafficking events at the membrane crucial for almost all aspects of neuronal polarity including migration, neurite outgrowth as well as axon and dendrite specifications. PTEN inhibits the signaling output of PI3Ks by dephosphorylating PIP3 back to PIP2 (PI(4,5)P2). The numerous modes of activation of PI3K by upstream signals and growth factors are not depicted. (B) PTEN is formed of 403 amino acids and its structure displays an N-terminal PIP2 binding motif (PBM), a phosphatase domain, a calcium-independent lipid-binding C2 domain, and a flexible C-terminal tail (Cter-tail) followed by a PDZ-binding motif (PDZ) (Lee et al., 1999; Shi et al., 2012; Song et al., 2012). The phosphatase and $C 2$ domains form a minimal structural unit that is capable of dephosphorylating PIP3 (Lee et al., 1999). Interestingly, highly unstructured elements such as the PBM, parts of the C2 domain and the C-terminal tail have important implications for the regulation of PTEN (Lee et al., 1999; Malaney et al., 2013). The phosphatase domain bears the P-loop signature motif of dual-specificity tyrosine phosphatases

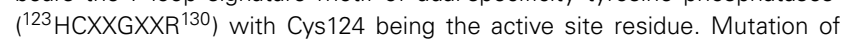
Cys124 to Ser renders PTEN inactive and this form of PTEN has been important to determine whether PTEN functions depend on its phosphatase activity (Myers et al., 1998). Interestingly, PTEN can also function as a protein phosphatase and putative protein substrates have been proposed in seminal studies (e.g., Tamura et al., 1998). The PTEN protein phosphatase activity can be equally important for autoregulation of PTEN and some PTEN functions pertinent to its tumor suppressive role, at least under certain settings (Tibarewal et al., 2012; Bassi et al., 2013). The positions of PTEN posttranslational modifications (ubiquitination and phosphorylation) as well as catalytic and membrane binding features (P-loop and CBR3-loop) that are discussed in the text are indicated.
Vanhaesebroeck et al., 2010). PI3Ks synthesize phosphatidylinositol 3,4,5-trisphosphate (PIP3) from phosphatidylinositol 4,5bisphosphate (PIP2), a phosphoinositide that is particularly enriched in the inner leaflet of the plasma membrane of all mammalian cells. In fact, it can be argued that this paradigm of extracellular signal/agonist-induced activation of PI3Ks represents perhaps the most prevalent signal transduction event associated with mammalian cell-surface receptor activation (Hawkins et al., 2006). Details concerning historical perspectives, mechanisms of activation, feedback regulatory mechanisms and crosstalk with other signaling modules, isoform-specific roles and downstream effectors of this prominent signaling pathway can be found in recent excellent reviews (Hawkins et al., 2006; Vanhaesebroeck et al., 2010, 2012). For the purpose of this review we will only 
highlight certain aspects of PI3K signaling that are key to understand the implications of PTEN function, particularly in neuronal cells.

\section{BASIC PRINCIPLES OF PI3K SIGNALING}

The major and primary output of PI3K signaling is PIP3. Its rapid synthesis upon PI3K activation coordinates the localization and function of multiple effector proteins, which utilize specific lipidbinding domains, such as $\mathrm{PH}$ (pleckstrin homology) domains, to recognize and bind this lipid on the plasma membrane. As suited for a second messenger, PIP3 is also subject to tight regulation by specific phosphoinositide phosphatases. PTEN is one of the most important phosphatases because it directly antagonizes the PI3K reaction by its 3-phosphatase activity and dephosphorylates PIP3 back to PIP2. In this sense, PTEN represents a brake built into PI3K signaling and its absence or dysfunction results in the constitutive and unregulated elevation of the signaling output of PI3Ks. Alternatively, PIP3 can be dephosphorylated by type II phosphoinositide 5-phosphatases like SH2-domain containing inositol 5-phosphatases 1 and 2 (SHIP1 and SHIP2) (Leslie et al., 2008). These enzymes generate PI3,4P2 (phosphatidylinositol 3,4-bisphosphate), which can be viewed as a secondary signaling output of PI3K. PI3,4P2 binds to sets of effector proteins that overlap with PIP3 effectors but also recruits others specifically (Vanhaesebroeck et al., 2010). Prominent PIP3 effectors and the pathways that relay PI3K signaling, as well as the domain structure of PTEN are briefly presented in the legend of Figure 1.

\section{BASIC PRINCIPLES OF PTEN REGULATION}

PTEN expression and activity is tightly regulated at almost all possible levels: transcriptionally, translationally, and posttranslationally (Shi et al., 2012; Song et al., 2012). Perhaps the most relevant mode of PTEN regulation, however, is through posttranslational modifications and interaction with other proteins. PTEN is modified by phosphorylation, acetylation, oxidation, Snitrosylation, ubiquitination, and sumoylation (Shi et al., 2012; Song et al., 2012; Bassi et al., 2013). A significant body of evidence now suggests that these posttranslational modifications may influence the phosphatase activity, the binding to the membrane, the localization to subcellular compartments, or the interaction with binding partners. For PTEN to fulfill its broad mechanisms of action ranging from regulation of proliferation to the establishment of defined neuronal circuits, it needs to be finely tuned both temporally and spatially. Interaction with PIP2/PIP3-rich plasma membrane domains is apparently an important feature of PTEN as a PIP3 phosphatase and we begin to form a comprehensive model of how this interaction is regulated. In addition, a surprising aspect of many recent findings has been that PTEN can be found in different cellular organelles. In this review, we focus specifically on the mechanisms of PTEN's association and recruitment to membranes, the function of PTEN in different subcellular compartments, how PTEN localizes in these specialized regions and why understanding the regulation of PTEN in these defined localized areas has become increasingly important in the context of neurological diseases.

\section{MECHANISMS OF PTEN CELL MEMBRANE ASSOCIATION AND RECRUITMENT PHOSPHOLIPID-SPECIFIC FUNCTIONS DURING ASSOCIATION OF PTEN WITH CELL MEMBRANES}

PTEN has been characterized as a highly plastic protein with strong intramolecular interactions and conformational changes that result from posttranslational modifications but also can occur as a consequence of interactions with other proteins or lipids. Under basal conditions, small concentrations of PTEN dynamically interact with the plasma membrane, a process that is abrogated following deletion of the N-terminal PBM (Vazquez et al., 2006). Distinct roles for the acidic phospholipids phosphatidylserine (PS), PIP2, and PIP3 in regulating PTEN at the membrane have been demonstrated. Whilst PIP2 interaction with the PBM seems to be the primary determinant of PTEN's plasma membrane localization (Rahdar et al., 2009; Shenoy et al., 2012), PS has been shown to support electrostatic attraction within the protein-membrane interface primarily via the C2 domain (Shenoy et al., 2012). Thus, PS and PIP2 appear to act synergistically in driving PTEN membrane interaction (Shenoy et al., 2012). PIP3, on the other hand, which binds to the phosphatase domain, does not appear to be a key determinant of PTEN's membrane association, at least when presented at physiological concentrations (Shenoy et al., 2012).

\section{REGULATION OF PTEN MEMBRANE ASSOCIATION BY CONFORMATIONAL CHANGES}

To date, the model that best explains the accessibility of PTEN to membranes suggests the presence of PTEN in two basic conformations, one of which is closed and the other open (Vazquez and Devreotes, 2006). The closed conformation is induced by an intramolecular association of the PTEN C-tail and part of the PTEN C2 domain (Figure 1B). Induction of the closed conformation is a process that occurs preferentially following phosphorylation of the PTEN C-tail (Odriozola et al., 2007; Rahdar et al., 2009; Ross and Gericke, 2009; Shenoy et al., 2012; Bolduc et al., 2013). Consequently, the open conformation of PTEN is thought to be unphosphorylated on the C-tail cluster, or at least to be less so. PTEN interactions with membranous PS and PIP2 may also induce conformational changes (Redfern et al., 2008; Shenoy et al., 2012), and it has been proposed that other secondary posttranslational modifications, such as sumoylation may provide a positive signal for PTEN membrane association (Huang et al., 2012). Therefore, levels of phosphorylation of the PTEN C-tail cluster at S/T 380-385, although highly informative, may not always faithfully report on PTEN's activation state.

\section{REGULATION OF PTEN MEMBRANE RECRUITMENT BY INTERACTING PROTEINS}

The recruitment of PTEN to membranes is further dictated through association with other proteins (Song et al., 2012). In this respect, transmembrane, peripheral membrane, and membraneassociated scaffold proteins that interact with PTEN are particularly important in positioning PTEN within close proximity to the membrane. In effect, such protein-protein interactions prime PTEN function toward membranous substrates (Sumitomo et al., 2004; Wu et al., 2007). Examples include the transmembrane 
protein NEP (Neutral Endopeptidase), which binds the phosphorylated PTEN C-tail via a highly positively charged cytosolic domain and recruits the phosphatase to the plasma membrane, enhancing both PTEN protein stability and activity (Sumitomo et al., 2004). PTEN has been also shown to interact with plasma membrane receptors of the tyrosine kinase and $\mathrm{G}$ protein-coupled receptor families, although it is not always clear if these interactions are direct (Sanchez et al., 2005; Fenton et al., 2012; Cao et al., 2013). In addition, several PDZ domain-containing proteins interact with the C-terminal PTEN PDZ-binding motif and recruit PTEN to the plasma membrane (Wu et al., 2000; Von Stein et al., 2005; Jurado et al., 2010; Molina et al., 2012; Terrien et al., 2012). PTEN-PDZ domain interactions may also serve in shifting PTEN into the open "active" conformation by sequestering the PTEN C-tail away from interacting with the C2-domain and unmasking the PTEN membrane-binding regions (Vazquez and Devreotes, 2006). However, PTEN recruitment to membrane proteins may also provide efficient "off"-switches for PIP3 hydrolysis by sequestering PTEN away from its substrate.

Membrane associated PTEN interacting proteins have further been described as PTEN adaptor proteins, since several of these facilitate PTEN's recruitment to activated receptors and places of highly restricted production of PIP3. Examples include NHERFs $(\mathrm{Na}(+) / \mathrm{H}(+)$ exchanger regulatory factors) or $\beta$-arrestins, which recruit PTEN to growth factor receptors (Lima-Fernandes et al., 2011; Molina et al., 2012). Interestingly, NHERF1, besides binding PTEN, also associates with the prominent Akt phosphatase PHLPP1 (PH domain and Leucine-rich repeat Protein Phosphatase), which leads to a synergistic attenuation of both PI3K-mediated PIP3 production as well as downstream Akt pathway activity (Molina et al., 2012). Efficient PI3K signaling feedback regulation during acute receptor tyrosine kinase signaling can be achieved by co-recruitment of PTEN with the regulatory subunit of PI3K class I enzymes, p85 $\alpha$ (Chagpar et al., 2010). In some of the interactions, the recruitment of PTEN to signaling complexes appears to be agonist-induced (Sanchez et al., 2005; Fenton et al., 2012). Therefore, a clear distinction can be made between PTEN-membrane protein interactions that appear to be constitutive and interactions that are agonistinduced. One can only surmise the latter to be spatially restricted to specific sites of active PI3K signaling.

\section{PTEN, LIPID RAFTS, AND ASSOCIATED MICRODOMAINS}

A further mode of membrane PTEN recruitment is orchestrated by lipid rafts or detergent-resistant membrane fractions in different cells such as cortical neurons, oligodendroglioma, and pheochromocytoma cell lines (Cheung et al., 2004; Goswami et al., 2005; Choy et al., 2006). Lipid rafts are specialized membrane microdomains involved in the compartmentalization of cellular processes and act as organizing centers for the assembly of signaling molecules. Two types of lipid rafts have been proposed: planar lipid rafts and caveolae. Planar rafts are defined as being continuous with the plane of the plasma membrane, whilst caveolae invaginate with the help of caveolin proteins. Planar rafts contain flotillin and are found in neurons where caveolae are absent. Both types of lipid rafts demonstrate similar lipid compositions that are enriched in cholesterol and sphingolipids. Lipid raft association of PTEN in neurons appears to be related to apoptosis either induced by lactacystin (Choy et al., 2006), or by treatment with $\mathrm{N}$-acetylsphingosine (C2ceramide) (Goswami et al., 2005). On the one hand, PTEN's recruitment to flotillin-rich plasma membrane domains was demonstrated during lactacystin-induced apoptosis in cortical neurons and verified by immunogold-TEM (Choy et al., 2006). On the other hand, PTEN has been found to associate with caveolin in immunoprecipitation experiments, which could account for recruitment to caveolin-rich subcellular fractions in caveolaepositive cell types (Caselli et al., 2002). In another study, PTEN was found to localize into the non-raft region of the plasma membrane (Gao et al., 2011). This localization was essential for allowing proper and robust activation of PDK1 and Akt in response to occurrence of growth factors receptor activation in the lipid raft region (Gao et al., 2011). Indeed, forced localization of constitutively activated PTEN to lipid rafts, or treatment with C2-ceramide (Goswami et al., 2005), was found to prevent growth factor-induced lipid raft restricted activation of PDK1 and Akt (Gao et al., 2011). Together, these studies suggest that activators and inhibitors of the PI3K pathway might be segregated to distinct sub-compartments at the level of the plasma membrane in dependence of the lipid raft composition. Nevertheless, the exact targeting mechanisms that segregate neuronal PTEN from lipid rafts, or that recruit PTEN into lipid rafts upon signaling, are currently unknown.

\section{PTEN MEMBRANE ASSOCIATION IN NEURONS}

PTEN and its associated PI3K signaling pathway have been shown to be particularly relevant in neurons during the control of cell growth, division, survival, and differentiation, in order to produce highly polarized neuronal morphologies with exquisite specializations such as growth cones and synapses. The proper localization of PTEN at the membrane is a key factor in the establishment of a PIP3/PIP2 gradient and the recruitment of important components necessary for the formation of growth cones and dendritic spines. PTEN is present in most, if not all, neurites during early neurite outgrowth, and in axons and dendrites in mature neurons. In particular, PTEN seems to be maintained at the microtubule-rich, central domain of growth cones with relatively low levels seen in the peripheral growth cone domain with its actin-rich filopodia and lamellipodia (Chadborn et al., 2006; Kreis et al., 2013; see Figure 2). Similarly, whilst PTEN-loss induces dramatic rearrangements in dendritic spine morphology and affects synaptic transmission, endogenous levels of PTEN are barely detectable in this neuronal compartment (Figure 3; Fraser et al., 2008; Kreis et al., 2010, 2013). These observations suggest that, specifically in neurons, PTEN may be sequestered away from the cell membrane and selectively recruited to the membrane under certain conditions. PTEN localization at the growth cone membrane has been shown to be mainly involved in the regulation of a PIP3 pool to induce chemorepulsion. On one hand, during Sema3A-induced growth cone collapse, neurite retraction, and chemorepulsion in dorsal root ganglion (DRG) growth cones, PTEN is recruited transiently and accumulates at the membrane, leading to decreases in PIP3 levels and an antagonistic effect on the PI3K signaling pathway (Chadborn et al., 


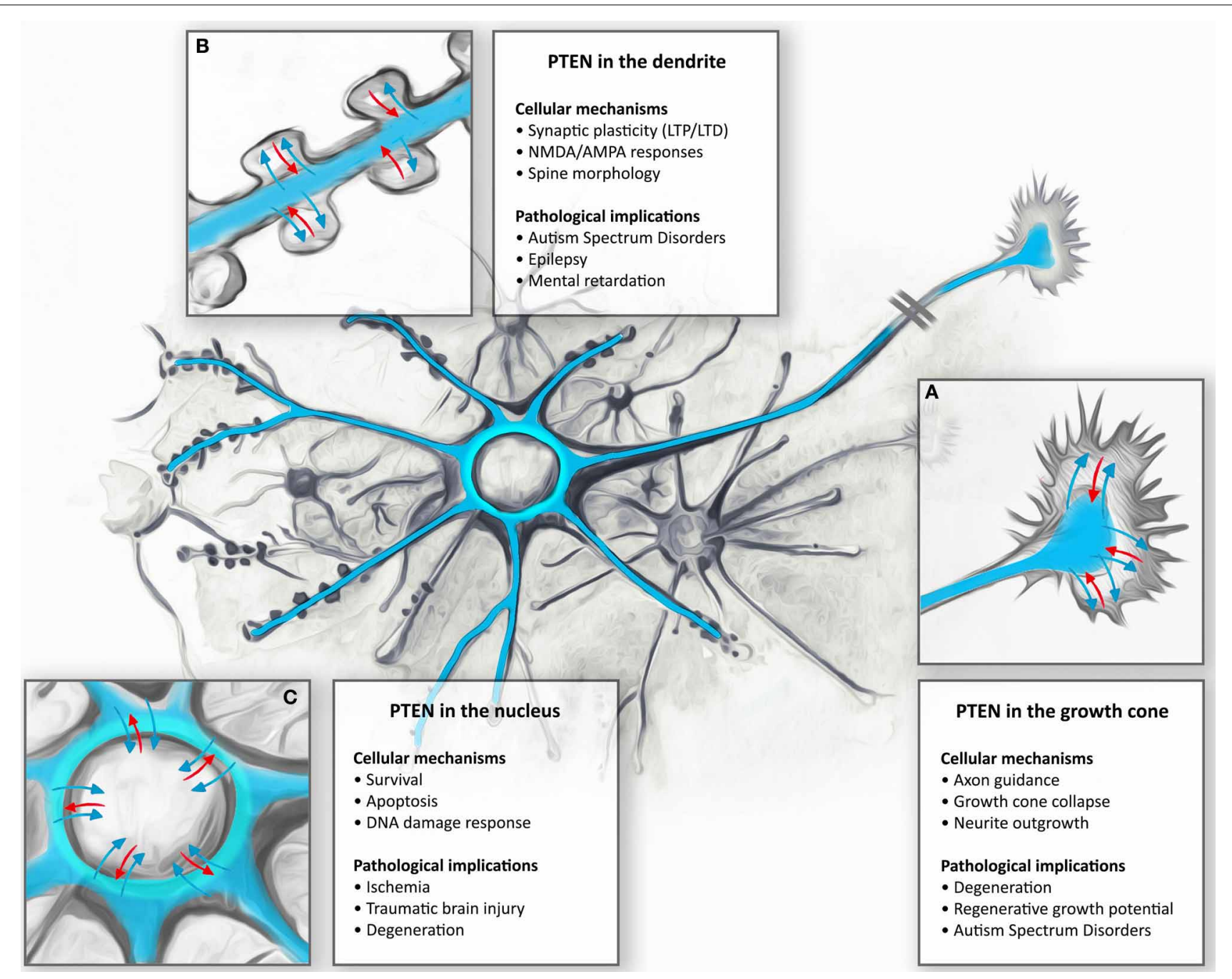

FIGURE 2 | Subcellular targeting and dynamic regulation of PTEN in neurons: Schematic illustration demonstrating dynamic distributions of PTEN in different neuronal compartments. (A) During neuronal development, PTEN is enriched in the axons and dendrites. Here, PTEN is thought to function in the regulation of growth cone dynamics during axonal navigation, in particular by inhibiting neurite outgrowth or mediating growth cone collapse responses. Consequently, PTEN-loss results in increased regenerative growth of axons in spinal cord injury models as well as protecting neurons during degeneration. (B) In mature CNS neurons PTEN is found in the dendrite. During NMDAR-dependent dendritic spine plasticity (long-term depression, LTD), PTEN translocates deep into the spine and anchors to the postsynaptic density. PTEN, by targeting membranous PIP3, also contributes to the dynamic changes in spine morphology during synapse development and plasticity. These synapse specific functions are thought to contribute to neurodevelopmental disorders such as autism, epilepsy, and mental retardation. (C) Nuclear PTEN has been reported to mediate neuronal survival or specifically induces apoptotic responses. Movement to the nucleus has been reported to occur during ischemia, traumatic brain injury, and degeneration; however, specific functions of these translocations are not clear.
2006). Along this vein, it has been suggested that PTEN is required for the activity of a number of established neurite outgrowth inhibitors, such as Sema3A, Sema4D. and Myelin-associated glycoprotein (MAG) in DRGs, hippocampal, cortical, and spinal neurons (Chadborn et al., 2006; Oinuma et al., 2010; Perdigoto et al., 2011; Henle et al., 2013). On the other hand, polarized increases in PIP3 at the leading edge of growth cones is an essential element of axonal growth and growth cone attraction (Henle et al., 2011). Accumulation of PIP3 has been seen also in axonal microdomains proximal to the growth cone. These PIP3 microdomains are induced by NGF (Nerve growth factor) in DRG neurons and they seem to be necessary for the formation of axonal
F-actin patches that support the generation of axonal filopodia (Ketschek and Gallo, 2010). Similarly, optogenetic control of PIP3 accumulation can induce the formation of active mobile F-actin lamellipodia-like structures in growth cones or along proximal axonal segments (Kakumoto and Nakata, 2013). These PIP3-rich membrane domains can be endocytosed, restricting downstream signaling components and thus leading to the modification of the size and function of the growth cone. Local accumulation of PIP3 is also important for axonal growth. Under basal conditions on a permissive laminin substrate, PIP3 levels are concentrated within the peripheral domain and fluctuate stochastically (Henle et al., 2013). However, upon exposure to chemoattractive growth 


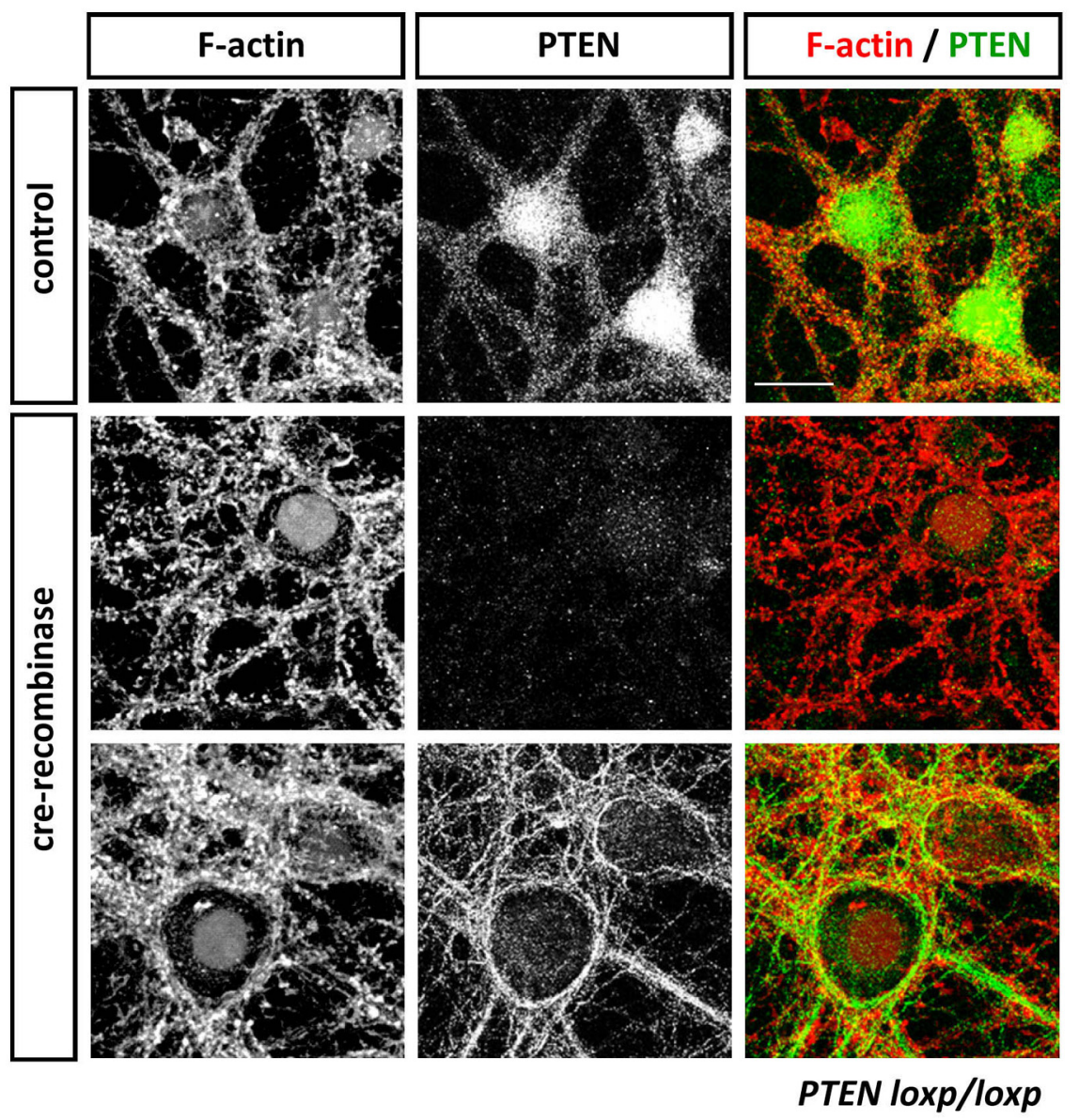

FIGURE 3 | Anti-PTEN antibodies do not always faithfully report on subcellular distributions of PTEN. Cortical neurons isolated from PTEN ${ }^{\text {flox/flox }}$ mice were transduced with control or Cre-expressing viruses at 13 days in vitro (DIV). Neurons were fixed with $4 \%$ parafolmaldehyde at 25 DIV, permeabilized with $0.1 \%$ Triton X-100 and stained with Phalloidin to visualize F-actin and anti-PTEN antibodies 138G6 (rabbit monoclonal from Cell Signaling Technology) and A2B1 (mouse monoclonal from Santa Cruz Biotechnogy). PTEN as detected with 138G6, (1:400 dilution) is highly enriched in the neuronal soma and dendrites, but it is largely absent in dendritic spines (first row). Cre-mediated recombination induced a PTEN-loss that resulted in well-established morphological changes in neuronal morphology including, for example, hypertrophy of the soma. In Cre-treated neurons, PTEN labeling using 138G6 was absent (second row), whilst the mouse A2B1 anti-PTEN antibody (third row) still retained strong labeling (although used at a high dilution of 1:1000). Note that the faint nuclear staining in control and Cre-recombinase treated neurons in F-actin images is due to nuclear RFP and RFP-Cre expressed, respectively, in these cells. Scale bar $=20 \mu \mathrm{m}$. guidance cues, PIP3 accumulation occurs in a polarized fashion toward the source of the cue (Henle et al., 2011). Thus, a feasible mechanism of PTEN functioning in neurons maybe to reinforce or re-sensitize PI3K-dependent signaling during growth factor promoted axonal elongation, as well as mediating axonal growth inhibition (Figure 2).

Using PIP3-specific Fluorescence resonance energy transfer (FRET) sensors to study the role of PIP3 at the synapse compartment, Ueda and Hayashi showed that PIP3 is primarily enriched in spines and not in dendritic shafts (Ueda and Hayashi, 2013). Upon chemical inhibition of PTEN, PIP3 was seen to accumulate preferentially in dendritic shafts rather than in spines, indicating that PTEN activity in the shaft region is higher while the opposite appears to apply for PI3K activity (Ueda and Hayashi, 2013). Small amounts of PTEN are present in the cytosolic compartment of spine heads, and in the plasma membrane away from the postsynaptic density (PSD) (Jurado et al., 2010). However, following NMDAR (N-methyl-D-aspartate receptor) stimulation, PTEN can be further enriched in the dendritic spine and anchored to the PSD primarily via PDZ-dependent interactions with PSD-95 (Jurado et al., 2010). Analysis of GFP-PTEN mobility in the spine has suggested that at least half of the PTEN spine pool is stable under basal conditions but, upon acute NMDAR activation there is increased mobility and eventually retention of PTEN into the spine (Jurado et al., 2010). Interestingly, deletion of the PDZ-binding domain of PTEN still results in increased mobility but abolishes the retention of PTEN into the spine (Jurado et al., 2010). It is conceivable that there is a basal diffusion of a small PTEN pool into spine that can then be retained and further targeted to the PSD in an activity-dependent manner. Thus, it appears that regulated PTEN localization in the spine and the PSD may be important for synapse-specific modulation 
of PIP3 signaling during synaptic plasticity. The recruitment and activation of PTEN at the membrane of neurons are important elements to the establishment of a localized PIP3/PIP2 balance necessary for specialized regions of the neurons to form and function in a required way. Other PIP3-independent roles of PTEN may also be important in this neuronal compartment, together they converge to allow the correct functioning of the synapse.

\section{EVIDENCE FOR PTEN ASSOCIATION WITH INTERNAL MEMBRANE COMPARTMENTS}

Based on the characteristic enrichments of PIP2 and PS in the inner leaflet of plasma membranes, the activity of membranebound PTEN is mostly confined to this compartment. However, a unique feature of PTEN is its ability to interact also with internal membrane containing organelles. The specific roles of PTEN at these membrane systems remains poorly understood. Because of the established link of these organelles to the pathology of different neurological conditions, we briefly review these relatively recent findings here.

\section{PTEN AND MITOCHONDRIA MEMBRANES}

PTEN localizes to mitochondria (Zhu et al., 2006; $\mathrm{Zu}$ et al., 2011; Bononi et al., 2013). In primary rat hippocampal neurons, PTEN's association to mitochondria membranes has been demonstrated by both immunohistochemistry and biochemical fractionation experiments, a localization that has been shown to increase during apoptotic stimuli, for example using staurosporine (Zhu et al., 2006). PTEN was found to interact with a member of the Bcl-2 (B-cell lymphoma 2) gene family, BAX, in co-immunoprecipitation experiments and this protein-protein interaction has been attributed to regulating the recruitment of PTEN to the outer mitochondrial membrane, at least during the initial phases of the response. A similar association of PTEN with Bax and mitochondria has been described recently in myocytes during ischemia-reperfusion ( $\mathrm{Zu}$ et al., 2011). Following induction with apoptotic stimuli, BAX becomes organelle membraneassociated, in particular, with mitochondrial membranes. On this basis, PTEN's transient association with BAX has been connected to mitochondria-dependent apoptotic death. But, as yet, specific mechanistic insight into a proposed PTEN connection has not been achieved.

\section{PTEN AND ENDOPLASMIC RETICULUM MEMBRANES}

A recent study demonstrated the presence of PTEN at the endoplasmic reticulum (ER) with apparent specific enrichment in mitochondria-associated membranes (MAMs) (Bononi et al., 2013). MAMs are distinct ER domains that support physical interaction between the ER and mitochondria and that are thought to be essential for efficient supply of $\mathrm{Ca}^{2+}$ from the ER to mitochondria (Fujimoto and Hayashi, 2011). Accordingly, they play major roles in both $\mathrm{Ca}^{2+}$-regulated mitochondrial bioenergetics and sensitivity to apoptosis, amongst other processes (Fujimoto and Hayashi, 2011). Sub-cellular localizations of PTEN to the ER and to MAMs were verified by immunostaining and biochemical fractionation experiments. An interaction of PTEN, as well as of Akt, with the ER inositol 1,4,5-trisphosphate receptor
(InsP3R) at the ER-MAM membranes-the membrane glycoprotein complex that acts as the $\mathrm{Ca}^{2+}$-channel activated by inositol trisphosphate-was detected (Bononi et al., 2013). Importantly, apoptotic stimuli enhanced the recruitment of PTEN to these InsP3R complexes, leading to reduced Akt activity and Aktdependent InsP3R phosphorylation and resulting in an increased $\mathrm{Ca}^{2+}$ release (Bononi et al., 2013). Specific targeting of PTEN to the ER was found to be sufficient to enhance ER-to-mitochondria $\mathrm{Ca}^{2+}$ transfer and sensitivity to apoptosis. Notably, this mechanism was dependent on the PTEN protein phosphatase activity and not the PTEN lipid phosphatase activity (Bononi et al., 2013). Although the mechanism of PTEN's recruitment to MAMs and non-MAM ER membranes remains unclear, it is likely that the PTEN-InsP3Rs association is involved. Whilst small PIP3 pools are present in ER membranes and mitochondria (Lindsay et al., 2006), no evidence has been provided that suggests PTEN actively regulates these pools (Bononi et al., 2013). Given the proximity of MAMs to mitochondria, it is also possible that some of the mitochondria-associated PTEN functions could be related to its localization in the MAMs. Interestingly, MAMs have been detected in neurons and synaptosomes and are important for neuronal ER-mitochondria communication as well as neuronal survival (Hedskog et al., 2013). Thus, PTEN targeted to ERMAMs in neurons could regulate mitochondria functions such as $\mathrm{Ca}^{2+}$ homeostasis or induce apoptotic signaling as implicated, for example, in neurodegenerative diseases such as Alzheimer's disease $(\mathrm{AD})$.

\section{PTEN, EXOSOMES, AND PTEN-LONG ISOFORM SECRETION}

Exosomes are bona fide secreted membrane organelles that contain cytosolic or endosomal proteins, and that are thought to provide essential intercellular communication. In this manner, exosomes serve as mediators to convey proteins, lipids and genetic information from one cell to another. Exosomes are formed in the cell in multivesicular endosomes that can fuse to the membrane to release their contents (Raposo and Stoorvogel, 2013). Recently, it has been shown that PTEN can be secreted in exosomes, exported in the extracellular compartment and taken up by recipient cells. This sequence of events has raised the exciting possibility that PTEN has non-cell-autonomous functions (Putz et al., 2012). Exosome-mediated PTEN secretion has been shown to require Ndfip (Nedd4 family interacting protein-1), an adaptor protein for E3 ubiquitin ligases, and an intact ubiquitination residue at PTEN K13 (Putz et al., 2012). PTEN loaded exosomes can inhibit the PI3K signaling pathway in recipient cells and decrease cellular proliferation (Putz et al., 2012). A further cellular strategy shown to generate secreted forms of PTEN is the presence of an additional sequence of 173 amino acids at the PTEN N-terminus (Hopkins et al., 2013). This PTEN-long phosphatase, translated from an alternative initiation codon upstream of the normal initiation codon, contains a secretion signal and a cell penetrating sequence and has the property to interact with cell surface proteins. When added as exogenous agent to cells in culture or injected intraperitoneally in mice, PTEN-long was able to decrease the activity of the PI3K signaling pathway. In addition, when injected in tumor mouse models, PTEN-long was able to induce tumor regression (Hopkins et al., 2013). 
The mechanisms underlying PTEN secretion require further exploration and may turn out to depend on the cell status or the cell type. Exosomes have been detected in neurons and glial cells, suggesting that they may serve as regulators of synaptic plasticity or participate in the propagation of pathological proteins responsible for neurodegenerative diseases (Chivet et al., 2013; Frühbeis et al., 2013). PTEN-loaded exosomes or PTEN-long expression could thus allow different intercellular exchanges within different brain regions, thereby modulating, for example, local changes in PI3K-mediated synaptic plasticity. Both forms of secreted PTEN appear to be physiologically and clinically significant as they can be readily detected in human blood (Gabriel et al., 2013; Hopkins et al., 2013).

\section{NUCLEAR FUNCTIONS OF PTEN}

Despite its well-established role in antagonizing PI3K signaling at the plasma membrane, PTEN has also been characterized as present in the nucleus of a number of cells, including fully differentiated neurons (Gimm et al., 2000; Lachyankar et al., 2000; Chadborn et al., 2006) (Figure 3). It appears that nuclear localization of PTEN is a dynamic process that correlates with cell cycle progression and/or the cellular differentiation state, and that it may be highly context dependent (Lian and Di Cristofano, 2005; Planchon et al., 2008; Song et al., 2012). In several cancer types, nuclear localization is a contributory factor to PTEN's tumor suppressor activity, for example, by maintaining chromosomal integrity (Shen et al., 2007), and regulating cellular survival (Chung et al., 2005; Gil et al., 2006), cell cycle, and DNA repair responses (Shen et al., 2007; Song et al., 2011; Bassi et al., 2013). Nuclear PTEN can also directly interact with p53 and alter transcriptional activity (Freeman et al., 2003). Importantly, recent studies have highlighted the importance of nuclear PTEN also in neurons, particularly in the context of neuronal survival (Figure 2). PTEN has been found to translocate to the nucleus during ischemia, traumatic brain injury (TBI) and during NMDA-induced excitotoxicity (Howitt et al., 2012; Goh et al., 2013; Zhang et al., 2013). In NMDA-challenged cortical neurons, translocation of PTEN to the nucleus is a delayed event, peaking at 6-9 h after treatment and with a decline after $24 \mathrm{~h}$ (Zhang et al., 2013). However, a persisted localization of PTEN in the nucleus of cells after $24 \mathrm{~h}$ has been observed in TBI models in cortical neurons (Goh et al., 2013). Whether nuclear PTEN functions as a pro-survival protein or whether it contributes to cell death remains controversial. For example, nuclear translocation of PTEN following TBI or cerebral ischemia (Howitt et al., 2012; Goh et al., 2013) does not seem to correlate with increased apoptosis in vivo; rather, it has been proposed that it might be a generic neuroprotective response of stressed neurons (Goh et al., 2013). Yet, in NMDA-challenged cortical neurons, inhibition of PTEN's nuclear translocation by a peptide designed to antagonize K13-ubiquitination of PTEN appears to be neuroprotective (Zhang et al., 2013). Further experiments are urgently needed to clarify the functions of nuclear PTEN in neurons since genetic or pharmacological PTEN inhibition is discussed as a promising approach to increasing neuroprotection in various settings (Ding et al., 2013; Mao et al., 2013). But how does PTEN function in the nucleus? Currently, there seems to be substantial evidence that at least some (if not most) of nuclear functions do not directly involve PTEN's PIP3 phosphatase activity (Song et al., 2012). PIP3 is present in the nucleus, as well as different PI3K isoforms and activated Akt, yet a detailed ultrastructural study suggested that the nuclear pool of PIP3 is not sensitive to hydrolysis by PTEN (Lindsay et al., 2006). Furthermore, given that PTEN's activity toward PIP3 requires structural interactions with membranes, it would be hard to reconcile this taking place in membrane-free, subnuclear compartments, where most of the nuclear PIP3 pool is located. Interestingly, a recent study suggested the possibility of different conformations adapted by cytosolic and nuclear PTEN, which may suggest phosphatase-independent functions for nuclear PTEN (Moncalero et al., 2011). Indeed, several nuclear PTEN functions that are relevant to its tumor suppressing role, such as control of the activity of the Anaphase Promoting Complex/Cyclosome (APC/C) and maintaining chromosomal integrity, do not require its lipid nor its protein phosphatase activity (Shen et al., 2007; Song et al., 2011). Other nuclear PTEN functions, however, have been shown to require at least its protein phosphatase activity (Bassi et al., 2013). Interestingly, NMDA treatment of cortical neurons, leads to nuclear PTEN translocation, resulting in decreases in PIP3 levels and Akt phosphorylation in this compartment (Zhang et al., 2013). However, whether nuclear PTEN in neurons is indeed active against nuclear PIP3 and thus regulates survival by inhibiting Akt remains to be tested.

\section{NUCLEAR TARGETING OF PTEN}

PTEN interacting proteins like MVP (Major Vault protein), the GTPase Ran, or the protein PNUFTS (a nuclear targeting subunit of PP1) may have a function in transporting or sequestering PTEN to the nucleus (Chung et al., 2005; Gil et al., 2006; Kavela et al., 2013). Nevertheless, the mechanisms of PTEN nucleo-cytoplasmic shuttling appear to primarily involve posttranslational modifications such as monoubiquitination or sumorylation (Trotman et al., 2007; Bassi et al., 2013). The phosphorylation of the C-terminus of PTEN has also been suggested to influence the cytoplasmic and nuclear localization of PTEN, which may be related to the conformation of PTEN modifying its potential to be ubiquitinated or to localize to membranes enriched in ubiquitin ligases (Vazquez et al., 2001; Gil et al., 2006; Maccario et al., 2010). Two PTEN monoubiquitination sites, K289 and K13, have been found to contribute to the localization of PTEN to the nucleus (Trotman et al., 2007; González-Santamaría et al., 2012; Zhang et al., 2013). Particularly in neurons, K13 alone appears to be important for PTEN nuclear localization (Zhang et al., 2013). However, K13 is also important for membrane association of PTEN as it is part of the PBM region (Walker et al., 2004; Figure 1B). Early studies indicated that the E3 ubiquitin ligase Nedd4 (neural precursor cell-expressed developmentally downregulated gene 4) can regulate monoubiquitination of PTEN and regulate PTEN's import into the nucleus (Trotman et al., 2007). Ndfipl, an adaptor for Nedd4-mediated ubiquitination and a direct binding partner of PTEN (Mund and Pelham, 2010) is also necessary for nuclear localization of PTEN in neurons (Howitt et al., 2012). A PTEN-deubiquitinating enzyme, HAUSP (herpesvirus-associated ubiquitin-specific protease) may serve in the deubiquitination of 
PTEN and its shuttling out of the nucleus (Song et al., 2008). To date, most Nedd4/PTEN studies in neurons have focused on the role of polyubiquitination in controlling PTEN abundance by the ubiquitin-proteasome system and identified that PTEN protein levels can be correlated with changes in survival or axonal growth and branching (Christie et al., 2010; Drinjakovic et al., 2010; Kwak et al., 2010).

\section{PTEN LOCALIZATION AND THE CYTOSKELETON}

In developing neurons, PI3K, PTEN, and Akt downstream signaling pathways are essential for most aspects of neuronal polarity, such as neurite outgrowth, axon and dendrite specification, growth cone guidance and migration (Waite and Eickholt, 2010). The intimate relationship of phosphoinositides and their impact on actin cytoskeleton dynamics stems from the fact that many proteins that are known to affect the actin-based cytoskeleton are acutely regulated by PIP2 and/or PIP3 (Yin and Janmey, 2003; Di Paolo and De Camilli, 2006). Indeed, PIP3 is regarded as a master regulator of Rho and Arf family-specific GEFs/GAPs (Hawkins et al., 2006) and its turnover is linked to initiation of cell migration and actin cytoskeleton reorganization, including, for example, the formation of structures like F-actin patches, lamellipodia and filopodia (Gallo, 2013; Kakumoto and Nakata, 2013; Karunarathne et al., 2013). The local balance between PIP2 and PIP3 may be essential during initiation and emergence of filopodia, as suggested by axonal filopodia biogenesis models (Gallo, 2013). Initial localized synthesis of PIP3 in membrane microdomains precedes and marks the position of actin patches (Ketschek and Gallo, 2010; Spillane et al., 2011). As PIP3 levels decline, increases in PIP2 may recruit the molecular machinery driving the emergence of a filopodium from the actin patch (Gallo, 2013). According to this model, dynamic hydrolysis of PIP3 to PIP2 by PTEN might be instrumental. However, analysis by immunostaining or live imaging of fluorescent PTEN constructs has rarely shown constitutive localization of PTEN in prominent F-actin structures, for example in the lamellipodia-rich leading edge of chemoattracting cells or in the peripheral zone of migrating growth cones (Li et al., 2005; Chadborn et al., 2006; Kreis et al., 2010). This is usually regarded as a sequestration of PTEN away from these sites in order to allow a steep PIP3 gradient to be formed and maintained, particularly during cell migration. In the case of growth cones and processes of neurons and neuronal cells, PTEN instead localizes rather prominently with microtubules (Chadborn et al., 2006) and recruitment to specific F-actin rich sub-plasmalemma domains may be driven by active transport mechanisms (Van Diepen et al., 2009; Kreis et al., 2010).

PTEN function has also been shown to be controlled by regulators of F-actin reorganization such as Rho family GTPases, Rac and Rho. P-Rex2a, a prominent Rac activator that is activated by PIP3, inhibits PTEN PIP3 phosphatase activity by direct interaction (Fine et al., 2009; Hodakoski et al., 2014), while active RhoA is thought to stimulate PTEN's PIP3 phosphatase activity, by ROCK-mediated phosphorylation of PTEN (Li et al., 2005). There is further a substantial degree of crosstalks and feedback loops embedded within the PI3K-PTEN-Rac/Rho GTPase network. Membranous PIP3, is able to activate RacGEFs, yet Rac is unique amongst Rho family GTPases in that it can directly activate specifically p $110 \beta$ PI3K, the only Ras-insensitive PI3K class I isoform (Fritsch et al., 2013). Furthermore, p110 PI3K can inhibit PTEN via RhoA/ROCK (Rho-associated protein kinase) (Eickholt et al., 2007; Papakonstanti et al., 2007). Another feature that adds complexity to the relationship of PTEN and the F-actin cytoskeleton is due to the fact that PIP3 can also be metabolized to PI3,4P2 by SHIP2 and other 5-phosphatases (Leslie et al., 2008). PI(3,4)P2 by itself is involved in many aspects of F-actin cytoskeleton reorganization by interaction with its specific effectors such as lamellipodin (Krause et al., 2004; Yoshinaga et al., 2012). Thus, PTEN may work in concert with 5-phosphatases in order to achieve precise regulation of the timing and extent of PI3K-generated PIP3 and PI3,4P2 at active sites of F-actin remodeling during neurite extension or growth cone dynamics (Aoki et al., 2007).

PTEN by itself interacts with actin cytoskeleton structural, accessory, or regulatory proteins, although, in most cases, the direct effects of PTEN activity or actin cytoskeleton function is not known. For example, PTEN was recently identified as part of a plasma membrane-associated actin remodeling complex composed of actin, gelsolin, and EPLIN (Epithelial Protein Lost In Neoplasm) (Kim et al., 2011b). Although it's unclear whether PTEN directly regulates the activity of the proteins in this complex, this association is proposed to be functional in regulating cell size checkpoint control in irradiated cells (Kim et al., 2011b). Early studies have shown that PTEN can regulate the integrin-mediated cell spreading and the formation of focal adhesions possibly by binding to focal adhesion kinase (FAK) and the downregulation of FAK tyrosin phosphorylation (Tamura et al., 1999, 1998). In addition, binding of PTEN to Bazooka/Par3 (Von Stein et al., 2005), can result in its recruitment to actin rich regions and the establishment of apical membrane identity by dephosphorylating PIP3 into PIP2 (Shewan et al., 2011). Interestingly, Bazzoka/Par3 can recruit PTEN via its PDZ3 domain and thus could relocate PTEN to PIP3/PIP2-rich domains recognized by its PDZ2 domain (Wu et al., 2007). Drebrin (Developmentally regulated brain protein) is another recently identified interacting protein of PTEN, which binds to actin filaments (Kreis et al., 2013). Drebrin is known to change the property of the actin cytoskeleton to control the formation of filopodia (Hayashi et al., 1996), potentially involving CDK5 (Cyclin-dependent kinase 5) mediated phosphorylation at S142 (Worth et al., 2013). Phosphorylation at another Drebrin site, S647, is targeted by PTEN in a PI3K-independent fashion in response to signals that induce a dynamic remodeling of the cytoskeleton (Kreis et al., 2013). Therefore, it has become increasingly clear that not all cytoskeleton-dependent processes regulated by PTEN depend on the PIP3 lipid phosphatase activity.

As described in previous sections, PTEN is dynamically localized to specialized sub-cellular compartments and organelles. This dynamic recruitment implies a tight temporal and spatial regulation and current evidence highlights the contribution of PTEN protein modifications and formation of distinct proteinprotein interactions in this process. Given the wide implication of PTEN in various pathological conditions, in the following sections, we attempt to summarize and emphasize the putative 
significance of compartmentalized PTEN pools in the progression of different neurodevelopmental diseases and neurodegenerative conditions.

\section{PTEN AND NEURODEVELOPMENTAL DISEASES PTEN HAMARTOMA TUMOR SYNDROME (PHTS)}

The term, PTEN hamartoma tumor syndromes (PHTS), refers to a collection of clinically distinct syndromes molecularly defined by germline PTEN mutations. These include Cowden syndrome (CS), Bannayan-Riley-Ruvalcaba syndrome (BRRS), Proteus syndrome (PS), and Proteus-like syndrome (PSL) (Eng, 2003; Mester and Eng, 2013). CS is a multiple hamartoma syndrome with a high risk for benign and malignant tumors. BRRS is associated with macrocephaly, intestinal hamartomatous polyposis, lipomas, and pigmented macules of the glans penis. PS is a complex and highly variable disorder involving congenital malformations and hamartomatous overgrowth of multiple tissues. PSL, in contrast, appears relatively undefined. It refers to individuals with significant clinical features of PS who do not meet the diagnostic criteria for this syndrome. Importantly, up to $85 \%$ of individuals who meet the diagnostic criteria for CS and 65\% of individuals with a clinical diagnosis of BRRS have detectable PTEN mutations (Eng, 2003). PTEN mutations appear also to be present in patients with PL and PLS, yet it has been suggested that patients with bona fide PS did not have PTEN mutations (Mester and Eng, 2013). Nevertheless, PI3K/PTEN/Akt/mTORC1 signaling seems to have a dominant role in the neurodevelopmental and overgrowth defects associated with this group of syndromes (Mester and Eng, 2013). Indeed, recent studies have reported the presence of activating mutations in Akt1 in PS (Lindhurst et al., 2011) and activating mutations in PIK3CA and Akt1 in a subset of CS (Orloff et al., 2013).

The majority of PTEN missense mutations found in PHTS occur in the phosphatase domain of PTEN (Eng, 2003; Mester and Eng, 2013) and most of these result in full or partial inactivation of PTEN's PIP3 activity (Eng, 2003; Rodríguez-Escudero et al., 2011). One particular mutation, G129E, originally identified in two independent CS kindreds, abolishes only the lipid phosphatase activity of PTEN, whilst the activity of the protein phosphatase is preserved (Myers et al., 1998). This characteristic has been instrumental in studying PIP3-dependent and -independent roles of PTEN (Raftopoulou et al., 2004; Tibarewal et al., 2012; Zhang et al., 2012a). Several PTEN mutations occur also in the C-terminal part of the protein (examples are F241S, P246L, K289E, R335L, V343E, L345V, F347L in the C2 domain). Some of these have been shown to reduce catalytic activity and membrane association (Rodríguez-Escudero et al., 2011) and/or have been shown to interfere with posttranslational modifications that are crucial for subcellular targeting of PTEN to the nucleus (Trotman et al., 2007). Phenotypes that can be associated with PTEN germline mutations also include Lhermitte-Duclos disease (LDD). Most, if not all, adult-onset LDD (dysplastic gangliocytoma of the cerebellum, a hamartomatous overgrowth known to be a feature of CS) can be attributed to mutations in PTEN, even in the absence of other clinical signs of CS/BRRS. However, germline PTEN mutations appear rare in individuals with childhood-onset LDD (Eng, 2003).
The PTEN-associated neurological deficits frequently observed in this group of syndromes are macrocephaly, developmental delay, and mental retardation. Ataxia, tremor, and epilepsy have been also reported (Lachlan et al., 2007; Conti et al., 2012; Mester and Eng, 2013; Pilarski et al., 2013). It should be noted, however, that no strong genotype-phenotype correlations are known in PHTS to date (Mester and Eng, 2013). Studies regarding the properties of mutated PTEN in PHTS are generally lacking, although some evidence suggests a correlation between PHTS and PTEN defect in a specific subcellular compartment. For example, the PTEN K289E mutation identified in CS disturbs the translocate of PTEN into the nuclei of patient tissue (Trotman et al., 2007). Another example relates to a mutation in the C2 domain, PTEN R335V which is also responsible for CS. This PTEN mutant enzyme retains normal levels of activity in cells (Rodríguez-Escudero et al., 2011), but its interaction with the lipid bilayer may be altered as suggested in a model of PTEN membrane association (Lumb and Sansom, 2013). Active research using molecular interaction simulation and modeling approaches, as well as functional screening of PTEN mutations in cell-based assays (Rodríguez-Escudero et al., 2011; Lumb and Sansom, 2013; Nguyen et al., 2013), will no doubt prove helpful in further clarifying the effects of PTEN mutations associated with PHTS.

\section{AUTISM SPECTRUM DISORDERS (ASD)}

PTEN has been established as one of the genetic factors that play a major role in autism spectrum disorders (ASD) (Zhou and Parada, 2012). ASD serves as an umbrella term for autism and related conditions pertinent to social-communication deficits, and restricted and repetitive behavior diagnosed in early childhood. Autism is also associated with sensory and motor abnormalities, sleep disturbance, epilepsy, attention deficit/hyperactivity disorder (ADHD)-like hyperactivity, intellectual disability, and mood disorders such as anxiety and aggression (Won et al., 2013). Germline PTEN mutations have been identified in $5-10 \%$ of autism patients, following the initial report that approximately $20 \%$ of individuals with autism spectrum disorders and macrocephaly carry germline PTEN mutations (Butler et al., 2005). Macrocephaly is also prevalent in PTHS patients with PTEN mutations (Mester et al., 2011; Mester and Eng, 2013) and it is one of the most frequent neuroanatomical abnormalities (20\%) observed in ASD individuals (Won et al., 2013).

Several PTEN mouse models have provided strong evidence for a causative role of PTEN dysfunction in almost all morphological, anatomical, synaptic, and behavioral manifestations relevant to ASD. Deletion of PTEN in neural progenitor cells and embryonic neural stem cells (Nestin-Cre:Pten ${ }^{\text {loxp/loxp }}$ ) results in increased neural stem cells proliferation, enlarged cell size, and brain enlargement (Groszer et al., 2001). Deletion of PTEN in GFAP (glial fibrillary acidic protein)-expressing neural progenitors, astrocytes, and a large subset of hippocampal neurons, cerebellar granule neurons, and cortical pyramidal neurons (Fraser et al., 2004, 2008) results in numerous structural abnormalities such as dramatic hypertrophy of nuclei, somata, axon, and dendritic caliber, enlarged presynaptic terminals, as well as absence or enlarged postsynaptic densities. Furthermore, the enlarged 
dendritic processes in Pten conditional knock out (cKO) mice showed a substantial increase in the density of spines and abnormal spine morphology (Fraser et al., 2008). Mice also developed progressive macrocephaly, seizures, and ataxia (Backman et al., 2001; Kwon et al., 2001). Although an increase in spine density was also observed following PTEN shRNA (short-hairpin RNA) treatments, there seems to be subtle difference when compared to genetically induced PTEN-loss (Luikart et al., 2011). In the basolateral amygdala and the dentate gyrus PTEN shRNA treatment resulted in increased mushroom spine density and spine size, with correspondingly decreased thin protrusion density at more distal segments (Haws et al., 2014). These results suggest that rather than inducing de novo spinogenesis per se, PTEN deletion may interfere with normal morphological and functional maturation of spines (Haws et al., 2014). Nevertheless, the most informative animal model related to ASD is the NSE-Cre:Pten ${ }^{\text {loxp/loxp }}$ mouse with postnatal deletion of PTEN in selected neuronal populations (Dentate gyrus granule cells, CA3 hippocampal neurons, and selected populations of cortical neurons). This PTEN cKO model recapitulates many of the late-onset morphological and behavioral abnormalities associated with autistic symptoms as these mice exhibit macrocephaly, neuronal hypertrophy, and deficits in hippocampus-based social and cognitive behavior, hypersensitivity to sensory stimuli, anxiety, and epileptic seizures (Kwon et al., 2006). Notably, autism-relevant behaviors are detectable at a time when morphological abnormalities seem relatively subtle (Kwon et al., 2006). Subsequent studies using a tamoxifen-inducible Nestin-Cre:Pten ${ }^{\text {loxp/loxp }}$ mouse model, in order to delete PTEN specifically in postnatal neural stem cells in the subgranular zone of hippocampal dentate gyrus, recapitulated the general overgrowth phenotype seen in other models and some, but not all of the impairments associated with autism (Amiri et al., 2012).

PTEN's role in regulating neuron morphology, gross anatomical changes and behavior is largely dependent on its lipid phosphatase activity. As such, in all PTEN KO and knockdown models studied to date, the major biochemical result of PTEN deletion invariably observed is an enhancement in Akt/mTORC1 signaling pathway activity. This is consistent with the primary defect of PTEN loss being an increase in PIP3 production and PI3K signaling. However, pharmacological inhibition of mTORC1 or co-deletion of PDK1 has been shown to reverse most-but not always all-phenotypes associated with PTEN deficiency in vivo (Zhou et al., 2009; Sperow et al., 2012). Although this could be due to subtle or specific requirements of PTEN's lipid phosphatase activity depending on the cellular or developmental context, it is also suggestive of, perhaps latent, PI3K-independent functional outputs of PTEN which are important for proper brain development.

\section{ASD-associated PTEN mutations}

The study of the mutational spectrum of PTEN in ASD patients has revealed at least 25 mutations to date, of which 16 are amino-acid substitutions (Table 1) (Rodríguez-Escudero et al., 2011; Klein et al., 2013; Hobert et al., 2014). More than half of these mutations have also been identified in PHTS patients or as somatic mutations in sporadic cancers. They are scattered along the PTEN phosphatase and the C2 domain, and are absent from the $\mathrm{N}$-terminal and the $\mathrm{C}$-terminal regions. The exact effect of ASD-unique mutations on the properties of PTEN (i.e., residual phosphatase activity, altered membrane/protein interactions, protein stability) is still poorly characterized. A number of recent studies have suggested the possibility that ASD mutations are less severe (i.e., mutant forms retain partial activity) when compared to tumor-related mutations. The mostly studied ASD mutation in the context of its effect on PTEN activity is PTEN H93R. This mutation also identified in CS, appears to result in an $85 \%$ decrease in PTEN's PIP3 phosphatase activity when measured against water-soluble PIP3 in vitro. Yet this mutation increased PTEN association with PS-rich liposomes in vitro, as well as increased membrane localization in vivo (Redfern et al., 2010). Notably, when compared to wild-type PTEN, PTEN H93R was unable to fully reduce PI3K-dependent Akt phosphorylation in U87MG glioblastoma cells, indicating a partial loss of activity in vivo (Redfern et al., 2010). Also, using a heterologous yeast PI3K-activity reconstitution system, PTEN H93R appeared to retain residual phosphatase activity when compared to PHTS PTEN mutants (Rodríguez-Escudero et al., 2011). Thus, it would appear that complete loss of PTEN phosphatase activity and/or PTEN stability is rather an infrequent event in ASD cases (Zhou and Parada, 2012). However, in addition to understanding the molecular effect of these ASD-unique mutations, their exact effect on the modulation of morphology and synaptic plasticity by PTEN awaits detailed analyses in neuronal cells.

\section{PTEN functions in dendritic spines}

Given the dominant effects of PTEN depletion on neuronal cell morphology and gross architecture of brain structures, it has been important to delineate the exact PTEN requirements for specific synaptic, behavioral and neuroanatomical defects observed in ASD-related PTEN mouse models. Importantly, a series of recent studies have highlighted that PTEN deletion results in specific early-onset deficits in postsynaptic plasticity that may even precede minor and gross anatomical changes. Depending on the experimental approach, the developmental stage and the mode of PTEN inactivation, loss of PTEN has been shown to result in changes in synaptic function including both forms of synaptic plasticity, long-term potentiation (LTP) and long-term depression (LTD) (Sperow et al., 2012; Takeuchi et al., 2013). Often, these changes are observed in the absence of the hypertrophy phenotypes that are characteristic of PTEN loss in postmitotic neurons (i.e., increases in soma size and dendritic spine density and dendrite arborization) (Sperow et al., 2012), suggesting that a primary role of PTEN is the regulation of synaptic function within the postsynaptic compartment. Thus, it is tempting to speculate that there is a spine-specific PTEN pool, which actively participates in the regulation of essential synaptic functions locally.

It has been suggested that a continuous turnover of PIP3 at the spine may support synaptic function, at least by maintaining synaptic retention of AMPAR ( $\alpha$-Amino-3-hydroxy-5-methyl-4isoxazolepropionic acid receptor) under basal conditions (Arendt et al., 2010). Furthermore, PI3K is activated upon LTP induction and it is also required for various forms of LTD (Kim et al., 
2011a). PTEN is recruited to the PSD upon NMDAR activation, primarily via PDZ-dependent interactions with PSD-95 (Jurado et al., 2010). In this case, it has been proposed that PTEN lipid phosphatase activity is able to drive depression of AMPARmediated synaptic responses. This activity is specifically required for NMDA receptor-dependent LTD (Jurado et al., 2010). Other studies have suggested that the recruitment of PTEN into the postsynaptic compartment may lead to modifications in proteins implicated in synaptic function involving specifically the protein phosphatase activity (Kreis et al., 2013). PTEN's protein phosphatase activity in neurons has been less well-characterized, although increasing evidence suggests that it may be important for regulating PTEN itself through auto-phosphorylation as well as through other protein substrates. For example, overexpression

\begin{tabular}{|c|c|c|c|c|c|}
\hline Mutation ${ }^{\mathrm{a}}$ & Macrocephalyb & Cancer $^{c}$ & Domain & Activity ${ }^{d}$ & Notes $^{e}$ \\
\hline M1I & + & & & & \\
\hline P38H & + & & Phosphatase & & \\
\hline Y68N & + & + & Phosphatase & & Y68D in PS \\
\hline L70V & + & & Phosphatase & & \\
\hline H93R & + & + & Phosphatase & ++ & $\mathrm{CS}$ \\
\hline H118P & + & & Phosphatase & ++ & \\
\hline $\mathrm{H} 1230$ & + & & Phosphatase & - & $\begin{array}{l}\text { H123D in CS, } \\
\text { P-loop }\end{array}$ \\
\hline R130L & + & + & Phosphatase & & $\begin{array}{l}\text { Frequently } \\
\text { mutated in } \\
\text { cancer, P-loop }\end{array}$ \\
\hline E157G & + & & Phosphatase & ++ & \\
\hline R173H & + & + & Phosphatase & ++ & $\begin{array}{l}\text { CS, } \\
\text { phosphatase- } \\
\text { C2 } \\
\text { interface }\end{array}$ \\
\hline Y176C & + & & Phosphatase & +++ & $\begin{array}{l}\text { CS, } \\
\text { phosphatase- } \\
\text { C2 } \\
\text { interface }\end{array}$ \\
\hline F241S & + & + & $\mathrm{C} 2$ & $-1+$ & CS \\
\hline V255A & + & + & C2 & & \\
\hline D252G & + & + & $\mathrm{C} 2$ & +++ & $\begin{array}{l}\text { Phosphatase- } \\
\text { C2 } \\
\text { interface }\end{array}$ \\
\hline N276S & + & & $\mathrm{C} 2$ & +++ & $\begin{array}{l}\text { Phosphatase- } \\
\text { C2 } \\
\text { interface }\end{array}$ \\
\hline D326N & + & & $\mathrm{C} 2$ & & \\
\hline
\end{tabular}

${ }^{a}$ Data from Rodríguez-Escudero et al. (2011), Hobert et al. (2014), Klein et al. (2013), Butler et al. (2005), Orrico et al. (2009), McBride et al. (2010), Varga et al. (2009), Buxbaum et al. (2007). Truncations R130X, L139X, Y178X, R335X, and R355X that presumably correspond to unstable/non-functional proteins are not included in the table.

${ }^{b}$ Association with macrocephaly.

COccurrence as somatic mutation in cancers (COSMIC database).

${ }^{d}$ Activity in the yeast system (Rodríguez-Escudero et al., 2011 - means no activity, +++ means full activity compared to wild type PTEN).

${ }^{e}$ Association with PHTS is indicated (PS, Proteus Syndrome; CS, Cowden Syndrome), as well as the catalytic or structural significance. of a protein phosphatase-deficient PTEN mutant, PTEN Y138L (Tibarewal et al., 2012), in organotypic hippocampal slice cultures does not phenocopy the effect of wild-type PTEN or PTEN G129E in reducing spine density (Zhang et al., 2012a). It has been suggested that autodephosphorylation of PTEN in this context may function in de-repressing the exposure of the C-terminal PDZbinding domain, thus allowing for PDZ domain-PTEN interactions to take place (Zhang et al., 2012a). Alternatively, PTEN's protein phosphatase activity could be directed to other protein substrates located in dendritic spines, such as Drebrin (Kreis et al., 2013). Drebrin phosphorylation at S647 is under the control of PTEN and it depends on direct complex formation of the two proteins and synaptic activity (Kreis et al., 2013). In conclusion, increasing the understanding of the molecular mechanisms that controls PTEN movement into and out of the postsynaptic compartment, and those that direct PTEN lipid/protein phosphatase activity might prove to be key to fully comprehend the impact of PTEN mutations associated with neurological disorders.

\section{PTEN AND AXON REGENERATION}

PTEN's role in regeneration became evident in a seminal study that induced genetic deletion of PTEN, specifically in adult retinal ganglion cells, which promoted regeneration of axonal fibers after subjection to an optic nerve crush injury (Park et al., 2008). Since then, research in finding ways to modify the expression or the activity of PTEN have become of great interest in this field. This might be particularly important for CNS neurons since axonal regeneration, contrary to neurons of the PNS (peripheral nervous system), is extremely limited following injury, which is due to both an inhibitory environment present at the side of injury as well as a general diminished regenerative capacity of affected neurons. Subsequent studies have shown that upon nerve transection of PNS neurons, axon outgrowth is enhanced following local inhibition of PTEN using the pharmacological PTEN inhibitor $\mathrm{BpV}(\mathrm{pic})$ or following siRNA knockdown of PTEN (Christie et al., 2010). PTEN loss using genetic deletion or shRNA approaches has also been shown to increase corticospinal tract sprouting, axon regeneration, and the enhanced formation of synaptic structures in models for spinal cord injury using unilateral pyramidotomy, dorsal hemisection, or complete spinal cord crush (Liu et al., 2010; Zukor et al., 2013).

For successful regeneration after an injury to occur, the injured axon tip must be remodeled to reform a growth cone. This transformation involves major changes in the cytoskeleton, as well as changes in membranous and cytoplasmic components that are necessary for the synthesis of new molecules. Several downstream effectors of PTEN have been shown to convey the information of axon regrowth. The PI3K/Akt/mTORC1 pathway, in particular, which regulates protein synthesis, is one of the important targets involved in axon regrowth. For example, pyramidotomy induces the loss of mTORC1 activity, an event that can be prevented by deletion of PTEN (Liu et al., 2010). Inhibition of mTORC1 using rapamycin largely neutralized the regenerative capacity of PTEN deleted neurons following axotomy (Park et al., 2008), suggesting that the injured axon tip benefits from increased mTORC1 activity in terms of the growth potential and regenerative growth. However, significant axon regeneration was still 
observed when inhibiting mTORC1, suggesting that other pathways may be involved (Park et al., 2008). Another study also suggested mTORC1-independent pathways, where the increased neurite outgrowth after PTEN deletion in the PNS, was not affected by rapamycin (Christie et al., 2010). Interestingly, combined activation of both the JAK/Stat and the PI3K/Akt/mTORC1 further increases the regenerative capacity of CNS neurons in the optic nerve crush model (Sun et al., 2011), demonstrating the significant interplay between different signaling pathways in promoting regenerative growth as well as neuronal survival (Luo and Park, 2012). Upstream of PTEN, signals mediated by inhibitors of axon growth such as MAGs or Sema3A could be responsible for preventing axon regeneration by activating PTEN. Indeed, deletion of PTEN resulted in a significant, although partial rescue of neurite outgrowth on MAG expressing $\mathrm{CHO}$ cells (Perdigoto et al., 2011).

The prospect to increase the regenerative capacity of damaged neurons by inhibiting PTEN has been of great interest for therapeutic strategies. In a mouse model for spinal muscular atrophy (SMA), the knock down of PTEN rescued disease associated defects in axon length, increased survival and restored growth cone sizes (Ning et al., 2010). Similarly, inhibition of PTEN using $\mathrm{BpV}$ (pic) has been shown to have a beneficial effect on spinal cord injuries, leading to increases in the number of motoneurons at the injury epicenter and improving forelimb articulation (Walker et al., 2012). Inhibition of PTEN may also be a promising target in amyotrophic lateral sclerosis (ALS), a well-studied degenerative motor neuron disease that that can be linked to inactivating mutations of the $\mathrm{Cu} / \mathrm{Zn}$ superoxide dismutase SOD1. Using microarray analysis of SOD1 deficient ALS spinal cord motor neurons, several components of the PI3K signaling pathway were identified to be dysregulated, which included PTEN (Kirby et al., 2011).

Collectively, these studies suggest that, at physiological settings, PTEN functions in restricting regenerative growth in the PNS and CNS neurons, and this is in agreement with PTEN's role in inhibiting the growth-promoting PI3K/Akt/mTORC1 pathway. Furthermore, it appears that deletion or inhibition of PTEN offers advanced neuroprotection by increasing neuronal survival. One of the key questions will entail the analyses of the minimal pool of PTEN that-once it is lost-induces regenerative growth response. Thus, unraveling the specific functions of PTEN in the different subcellular compartments of neurons should bring new insights into the mechanisms necessary for the establishment of a robust and sustained regeneration.

\section{PTEN AND NEURODEGENERATIVE CONDITIONS PTEN AND ALZHEIMER'S DISEASE}

$\mathrm{AD}$ involves the degeneration of neurons and the accumulation of pathological highly phosphorylated Tau protein species, which eventually generate neurofibrillary tangles. The driving force for $\mathrm{AD}$, however, involves the overproduction of the amyloid $\beta$-peptides that form the extracellular deposits found in the brains of patients with $\mathrm{AD}$, the amyloid plaques. It was initially shown that stimulation of the PI3K/Akt signaling pathway in vitro through insulin-like growth factor may protect $A \beta$ induced neurotoxicity (Doré et al., 1997; Wei et al., 2002). This was in line with the fact that GSK-3, which operates downstream of the
PI3K signaling pathway, had been identified as a potential kinase responsible for causing hyper-phosphorylation of Tau (Hanger et al., 1992). Later, the function of PI3K in neuronal survival and $\mathrm{AD}$ showed the requirement of a more defined coordination of the different components of the pathway. Contrary to initial expectations, an overactivation of PI3K signaling was reported in postmortem brain tissue in both immunohistochemistry and immunobiochemistry with an increase in Akt activation, a loss of neuronal cytosolic Akt and a loss and modified localization of PTEN in the temporal cortex and hippocampus of AD patients (Griffin et al., 2005). Interestingly, a loss of nuclear PTEN was observed in neurons of the CA1, subiculum, and entorhinal cortex, as well as in the temporal cortex of AD cases (Griffin et al., 2005). In agreement with this, another study showed that PTEN re-distributed from the nucleus to the cytoplasm in regions such as the hippocampus and the entorhinal cortex of $\mathrm{AD}$ tissue and accumulated in intracellular neurofibrillary tangles (Sonoda et al., 2010). It has been suggested that the overactivation of the PI3K signaling pathway and the observed decreases in PTEN protein levels originate from a pro-survival response aimed at compensating for the disease. Decreased PTEN protein abundances may also impact on the phosphorylation state of Tau. Indeed, the lipid phosphatase activity of PTEN may affect Tau phosphorylation as in vitro studies have shown that PTEN can affect the formation of Tau aggregates in a GSK3-independent manner (Kerr et al., 2006; Zhang et al., 2006). The exact function of PTEN in Alzheimer disease remains, however, poorly understood, due to the complexity of the disease and the existence of numerous compensatory feedback loops within the PI3K signaling pathway. Decisive proof of whether the observed loss of PTEN in the nucleus in AD tissue leads to an apoptotic or a prosurvival signal remains elusive. Similarly, detailed information on the function of PTEN and/or its modified localization in other subcellular compartments such as the ER, the mitochondria or the MAMs are still not available. Nevertheless, PTEN may play a key role in the regulation of calcium signaling and apoptotic responses that are both perturbed in $\mathrm{AD}$ and are associated with these compartments. For instance, as mentioned in the previous section, PTEN recruited at the MAM-ER membranes (Bononi et al., 2013) could have an effect on modification in the calcium transfer from the ER to the mitochondria that has been observed following $A \beta$ treatment (Hedskog et al., 2013). A similar contribution of PTEN could potentially relate to its interaction with the pro-apoptotic protein Bax at the mitochondria and regulation of apoptotic signaling pathways (Zu et al., 2011). Again, these ideas, though plausible, have not yet been tested in the context of $\mathrm{AD}$ research.

\section{PTEN AND PARKINSON'S DISEASE}

Parkinson's disease (PD) is the second most prevalent neurodegenerative disorder after Alzheimer's. It is characterized by progressive loss of dopaminergic neurons in the substantia nigra pars compacta. Earlier studies provided links for PTEN's involvement in the pathogenesis of PD by virtue of its indirect and direct interactions, respectively, with two prominent $\mathrm{PD}$-associated genes, PINK1 and DJ-1. However, more recent studies utilizing primarily neuron subtype-specific PTEN cKO mice have suggested diverse roles for PTEN and the Akt/mTOR pathway in 
dopaminergic neurons. It has been shown, for instance, that inhibition of PTEN in dopaminergic cell lines significantly inhibits the neuronal death caused by 1-methyl-4-phenylpyridinium $(\mathrm{MPP}+)$, an established in vitro model of PD toxicity (Zhu et al., 2007). Dopaminergic neuron-specific deletion of PTEN recapitulated the hypertrophy phenotype observed in other cKO mouse models (Diaz-Ruiz et al., 2009). In addition, PTEN inactivation protected dopaminergic neurons and significantly enhanced dopamine-dependent behavioral functions in cKO mice after a progressive 6-hydroxydopamine (6OHDA) lesion, where application of this neurotoxin into the striatum results in progressive loss of neurons in the ventral mesencephalon (Diaz-Ruiz et al., 2009). Subsequent studies in adult mice using an inducible Cre system showed that specific ablation of PTEN in adult dopaminergic neurons is neuroprotective in genetic and neurotoxin-induced mouse models of PD (Domanskyi et al., 2011). In this case, PTEN deletion attenuated the loss of tyrosine hydroxylase-positive cells after 6OHDA treatment. Also, specific ablation of an essential factor controlling ribosomal RNA transcription, Tifla, in adult mouse dopaminergic neurons represses mTOR signaling and leads to progressive neurodegeneration and PD-like phenotype. Here, PTEN deletion rescued locomotor impairments caused by absence of Tifla (Domanskyi et al., 2011). These more recent studies are in accordance with an earlier report showing that overactivation of PI3K signaling, by adenoviral transduction of a membrane-localized Akt1 form into substantia nigra neurons, offers protection against 6OHDA (Ries et al., 2006). Another example of the general applicability and beneficial effects of PTEN deletion in PD mouse models is the enhanced survival, function and integration of grafted $\mathrm{PTEN}^{-/-}$dopaminergic neurons within the striatum of MitoPark mice, a model that shows progressive parkinsonism after specific inactivation of the mitochondrial respiratory chain in midbrain dopaminergic neurons (Zhang et al., 2012b).

A specific requirement for PTEN in the regulation of axon terminal morphology of dopaminergic neurons has been uncovered in neurons deficient in an essential macroautophagy component, Atg7 (Inoue et al., 2013). In these mice, midbrain dopaminergic neurons exhibit strikingly enlarged axon terminals and also late-onset degeneration in vivo. Interestingly, although PTENdeficient dopaminergic neurons show no alteration at the axon terminal, concomitant deletion of PTEN and Atg7 results in a exacerbation of the axon terminal size seen in Atg7 deficient neurons in the absence of any degeneration phenotype (Inoue et al., 2013). These results suggest that macroautophagic activity, at least in dopaminergic neurons, may limit the impact of PTEN/PI3K/mTOR pathway on axon terminal morphology (Inoue et al., 2013).

In conclusion, an overall protective effect against neuronal death has been demonstrated when PTEN is deleted or inactivated in dopaminergic neurons, which is likely to reflect a generalized response due to activation of the PI3K/Akt/mTOR signaling pathway.

\section{CONCLUDING REMARKS}

Numerous specific modes of PTEN functions have been identified that are restricted to diverse subcellular compartments and involved in mediating a plethora of cellular responses. It has become increasingly clear that PTEN functions are not exclusively restricted to targeting phosphoinositides in membranous compartments; instead, PTEN specific cellular responses also involve its protein phosphatase activity or, no phosphatase activity at all. On one hand, PTEN inhibition has become a potentially attractive therapeutic intervention in certain settings. Yet, on the other hand, PTEN activation could be beneficial in other conditions. So far, chemical compounds that can act as PTEN inhibitors have been shown to substantially corroborate findings from studies utilizing deletion and silencing approaches. In principal, rational design of chemical compounds or peptides to shift, or prevent PTEN's localization to a specific subcellular compartment, to alter binding to a prominent protein partner, or to impose specific structural conformations on PTEN are plausible. Furthermore, the implications of using PTEN itself as an exogenous factor are only now beginning to be appreciated. In this review, we have attempted to detail some of the roles of PTEN that are, or may turn out to be involved, in mediating cellular responses in the developing, the mature, as well as the diseased neuron. No doubt, the interplay between the mechanisms that coordinate subcellular targeting in the context of controlling enzymatic activity will require detailed attention and have to be further explored.

\section{ACKNOWLEDGMENTS}

This work was funded by a grant of the Biotechnology and Biological Science Research Council to Britta J. Eickholt and Ivo Lieberam (BB/I022392/1). We thank members of the Britta J. Eickholt lab for helpful discussions.

\section{REFERENCES}

Amiri, A., Cho, W., Zhou, J., Birnbaum, S. G., Sinton, C. M., McKay, R. M., et al (2012). Pten deletion in adult hippocampal neural stem/progenitor cells causes cellular abnormalities and alters neurogenesis. J. Neurosci. 32, 5880-5890. doi: 10.1523/JNEUROSCI.5462-11.2012

Aoki, K., Nakamura, T., Inoue, T., Meyer, T., and Matsuda, M. (2007). An essential role for the SHIP2-dependent negative feedback loop in neuritogenesis of nerve growth factor-stimulated PC12 cells. J. Cell Biol. 177, 817-827. doi: 10.1083/jcb.200609017

Arendt, K. L., Royo, M., Fernández-Monreal, M., Knafo, S., Petrok, C. N., Martens, J. R., et al. (2010). PIP3 controls synaptic function by maintaining AMPA receptor clustering at the postsynaptic membrane. Nat. Neurosci. 13, 36-44. doi: $10.1038 / \mathrm{nn} .2462$

Backman, S. A., Stambolic, V., Suzuki, A., Haight, J., Elia, A., Pretorius, J., et al. (2001). Deletion of Pten in mouse brain causes seizures, ataxia and defects in soma size resembling Lhermitte-Duclos disease. Nat. Genet. 29, 396-403. doi: $10.1038 / \mathrm{ng} 782$

Bassi, C., Ho, J., Srikumar, T., Dowling, R. J. O., Gorrini, C., Miller, S. J., et al. (2013). Nuclear PTEN controls DNA repair and sensitivity to genotoxic stress. Science 341, 395-399. doi: 10.1126/science.1236188

Bolduc, D., Rahdar, M., Tu-Sekine, B., Sivakumaren, S. C., Raben, D., Amzel, L. M., et al. (2013). Phosphorylation-mediated PTEN conformational closure and deactivation revealed with protein semisynthesis. Elife 2:e00691. doi: 10.7554/eLife.00691

Bononi, A., Bonora, M., Marchi, S., Missiroli, S., Poletti, F., Giorgi, C., et al. (2013). Identification of PTEN at the ER and MAMs and its regulation of $\mathrm{Ca}(2+)$ signaling and apoptosis in a protein phosphatase-dependent manner. Cell Death Differ. 20, 1631-1643. doi: 10.1038/cdd.2013.77

Butler, M. G., Dasouki, M. J., Zhou, X.-P., Talebizadeh, Z., Brown, M., Takahashi, T. N., Miles, J. H., Wang, C. H., Stratton, R., Pilarski, R., et al. (2005). Subset of individuals with autism spectrum disorders and extreme macrocephaly associated with germline PTEN tumour suppressor gene mutations. J. Med. Genet. 42, 318-321. doi: 10.1136/jmg.2004.024646 
Buxbaum, J. D., Cai, G., Chaste, P., Nygren, G., Goldsmith, J., Reichert, J., et al. (2007). Mutation screening of the PTEN gene in patients with autism spectrum disorders and macrocephaly. Am. J. Med. Genet. B Neuropsychiatr. Genet. 144B, 484-491. doi: 10.1002/ajmg.b.30493

Cao, J., Wan, L., Hacker, E., Dai, X., Lenna, S., Jimenez-Cervantes, C., et al. (2013). MC1R is a potent regulator of PTEN after UV exposure in melanocytes. Mol. Cell 51, 409-422. doi: 10.1016/j.molcel.2013.08.010

Caselli, A., Mazzinghi, B., Camici, G., Manao, G., and Ramponi, G. (2002). Some protein tyrosine phosphatases target in part to lipid rafts and interact with caveolin-1. Biochem. Biophys. Res. Commun. 296, 692-697. doi: 10.1016/S0006291X(02)00928-2

Chadborn, N. H., Ahmed, A. I., Holt, M. R., Prinjha, R., Dunn, G. A., Jones, G. E., et al. (2006). PTEN couples Sema3A signalling to growth cone collapse. J. Cell Sci. 119, 951-957. doi: 10.1242/jcs.02801

Chagpar, R. B., Links, P. H., Pastor, M. C., Furber, L. A., Hawrysh, A. D., Chamberlain, M. D., et al. (2010). Direct positive regulation of PTEN by the p85 subunit of phosphatidylinositol 3-kinase. Proc. Natl. Acad. Sci. U.S.A. 107, 5471-5476. doi: 10.1073/pnas.0908899107

Cheung, N. S., Choy, M. S., Halliwell, B., Teo, T. S., Bay, B. H., Lee, A. Y., et al. (2004). Lactacystin-induced apoptosis of cultured mouse cortical neurons is associated with accumulation of PTEN in the detergent-resistant membrane fraction. Cell Mol. Life Sci. 61, 1926-1934. doi: 10.1007/s00018-004-4127-7

Chivet, M., Javalet, C., Hemming, F., Pernet-Gallay, K., Laulagnier, K., Fraboulet, S., et al. (2013). Exosomes as a novel way of interneuronal communication. Biochem. Soc. Trans. 41, 241-244. doi: 10.1042/BST20120266

Choy, M. S., Bay, B. H., Cheng, H. C., and Cheung, N. S. (2006). PTEN is recruited to specific microdomains of the plasma membrane during lactacystin-induced neuronal apoptosis. Neurosci. Lett. 405, 120-125. doi: 10.1016/j.neulet.2006.06.037

Christie, K. J., Webber, C. A., Martinez, J. A., Singh, B., and Zochodne, D. W. (2010). PTEN inhibition to facilitate intrinsic regenerative outgrowth of adult peripheral axons. J. Neurosci. 30, 9306-9315. doi: 10.1523/JNEUROSCI.6271-09.2010

Chung, J.-H., Ginn-Pease, M. E., and Eng, C. (2005). Phosphatase and tensin homologue deleted on chromosome 10 (PTEN) has nuclear localization signallike sequences for nuclear import mediated by major vault protein. Cancer Res. 65, 4108-4116. doi: 10.1158/0008-5472.CAN-05-0124

Conti, S., Condò, M., Posar, A., Mari, F., Resta, N., Renieri, A., et al. (2012). Phosphatase and tensin homolog (PTEN) gene mutations and autism: literature review and a case report of a patient with Cowden syndrome, autistic disorder, and epilepsy. J. Child Neurol. 27, 392-397. doi: 10.1177/0883073811420296

Costa-Mattioli, M., and Monteggia, L. M. (2013). mTOR complexes in neurodevelopmental and neuropsychiatric disorders. Nat. Neurosci. 16, 1537-1543. doi: 10.1038/nn.3546

Diaz-Ruiz, O., Zapata, A., Shan, L., Zhang, Y., Tomac, A. C., Malik, N., et al. (2009). Selective deletion of PTEN in dopamine neurons leads to trophic effects and adaptation of striatal medium spiny projecting neurons. PloS ONE 4:e7027. doi: 10.1371/journal.pone.0007027

Ding, J., Guo, J., Yuan, Q., Yuan, F., Chen, H., and Tian, H. (2013). Inhibition of phosphatase and tensin homolog deleted on chromosome 10 decreases rat cortical neuron injury and blood-brain barrier permeability, and improves neurological functional recovery in traumatic brain injury model. PloS ONE 8:e80429. doi: 10.1371/journal.pone.0080429

Di Paolo, G., and De Camilli, P. (2006). Phosphoinositides in cell regulation and membrane dynamics. Nature 443, 651-657. doi: 10.1038/nature05185

Domanskyi, A., Geissler, C., Vinnikov, I. A., Alter, H., Schober, A., Vogt, M. A., et al. (2011). Pten ablation in adult dopaminergic neurons is neuroprotective in Parkinson's disease models. FASEB J. 25, 2898-2910. doi: 10.1096/fj.11-181958

Doré, S., Kar, S., and Quirion, R. (1997). Insulin-like growth factor I protects and rescues hippocampal neurons against beta-amyloid- and human amylininduced toxicity. Proc. Natl. Acad. Sci. U.S.A. 94, 4772-4777.

Drinjakovic, J., Jung, H., Campbell, D. S., Strochlic, L., Dwivedy, A., and Holt, C. E. (2010). E3 ligase Nedd4 promotes axon branching by downregulating PTEN. Neuron 65, 341-357. doi: 10.1016/j.neuron.2010.01.017

Eickholt, B. J., Ahmed, A. I., Davies, M., Papakonstanti, E. A., Pearce, W., Starkey, M. L., et al. (2007). Control of axonal growth and regeneration of sensory neurons by the p110delta PI 3-kinase. PLoS ONE 2:e869. doi: 10.1371/journal.pone.0000869

Eng, C. (2003). PTEN: one gene, many syndromes. Hum. Mutat. 22, 183-198. doi: 10.1002/humu.10257
Fenton, T. R., Nathanson, D., Ponte de Albuquerque, C., Kuga, D., Iwanami, A., Dang, J., et al. (2012). Resistance to EGF receptor inhibitors in glioblastoma mediated by phosphorylation of the PTEN tumor suppressor at tyrosine 240. Proc. Natl. Acad. Sci. U.S.A. 109, 14164-14169. doi: 10.1073/pnas.1211962109

Fine, B., Hodakoski, C., Koujak, S., Su, T., Saal, L. H., Maurer, M., et al. (2009). Activation of the PI3K pathway in cancer through inhibition of PTEN by exchange factor P-REX2a. Science 325, 1261-1265. doi: 10.1126/science.1173569

Fraser, M. M., Bayazitov, I. T., Zakharenko, S. S., and Baker, S. J. (2008). Phosphatase and tensin homolog, deleted on chromosome 10 deficiency in brain causes defects in synaptic structure, transmission and plasticity, and myelination abnormalities. Neuroscience 151, 476-488. doi: 10.1016/j.neuroscience.2007.10.048

Fraser, M. M., Zhu, X., Kwon, C.-H., Uhlmann, E. J., Gutmann, D. H., and Baker, S. J. (2004). Pten loss causes hypertrophy and increased proliferation of astrocytes in vivo. Cancer Res. 64, 7773-7779. doi: 10.1158/0008-5472.CAN-04-2487

Freeman, D. J., Li, A. G., Wei, G., Li, H.-H., Kertesz, N., Lesche, R., et al. (2003). PTEN tumor suppressor regulates p53 protein levels and activity through phosphatase-dependent and -independent mechanisms. Cancer Cell 3, 117-130. doi: $10.1016 / S 1535-6108(03) 00021-7$

Fritsch, R., de Krijger, I., Fritsch, K., George, R., Reason, B., Kumar, M. S., et al. (2013). RAS and RHO families of GTPases directly regulate distinct phosphoinositide 3-kinase isoforms. Cell 153, 1050-1063. doi: 10.1016/j.cell.2013.04.031

Frühbeis, C., Fröhlich, D., Kuo, W. P., and Krämer-Albers, E.-M. (2013). Extracellular vesicles as mediators of neuron-glia communication. Front. Cell. Neurosci. 7:182. doi: 10.3389/fncel.2013.00182

Fujimoto, M., and Hayashi, T. (2011). New insights into the role of mitochondriaassociated endoplasmic reticulum membrane. Int. Rev. Cell Mol. Biol. 292, 73-117. doi: 10.1016/B978-0-12-386033-0.00002-5

Gabriel, K., Ingram, A., Austin, R., Kapoor, A., Tang, D., Majeed, F., et al. (2013). Regulation of the tumor suppressor PTEN through exosomes: a diagnostic potential for prostate cancer. PloS ONE 8:e70047. doi: 10.1371/journal.pone. 0070047

Gallo, G. (2013). More than one ring to bind them all: recent insights into the structure of the axon. Dev. Neurobiol. 73, 799-805. doi: 10.1002/dneu.22100

Gao, X., Lowry, P. R., Zhou, X., Depry, C., Wei, Z., Wong, G. W., et al. (2011). PI3K/Akt signaling requires spatial compartmentalization in plasma membrane microdomains. Proc. Natl. Acad. Sci. U.S.A. 108, 14509-14514. doi: 10.1073/pnas. 1019386108

Gil, A., Andrés-Pons, A., Fernéndez, E., Valiente, M., Torres, J., Cervera, J., et al. (2006). Nuclear localization of PTEN by a Ran-dependent mechanism enhances apoptosis: involvement of an $\mathrm{N}$-terminal nuclear localization domain and multiple nuclear exclusion motifs. Mol. Biol. Cell 17, 4002-4013. doi: 10.1091/mbc.E06-05-0380

Gimm, O., Perren, A., Weng, L. P., Marsh, D. J., Yeh, J. J., Ziebold, U., et al. (2000). Differential nuclear and cytoplasmic expression of PTEN in normal thyroid tissue, and benign and malignant epithelial thyroid tumors. Am. J. Pathol. 156, 1693-1700. doi: 10.1016/S0002-9440(10)65040-7

Goh, C.-P., Putz, U., Howitt, J., Low, L.-H., Gunnersen, J., Bye, N., et al. (2013). Nuclear trafficking of Pten after brain injury leads to neuron survival not death. Exp. Neurol. 252C, 37-46. doi: 10.1016/j.expneurol.2013.11.017

González-Santamaría, J., Campagna, M., Ortega-Molina, A., Marcos-Villar, L., de la Cruz-Herrera, C. F., González, D., et al. (2012). Regulation of the tumor suppressor PTEN by SUMO. Cell Death Dis. 3, e393. doi: 10.1038/cddis. 2012.135

Goswami, R., Singh, D., Phillips, G., Kilkus, J., and Dawson, G. (2005). Ceramide regulation of the tumor suppressor phosphatase PTEN in rafts isolated from neurotumor cell lines. J. Neurosci. Res. 81, 541-550. doi: 10.1002/jnr.20550

Griffin, R. J., Moloney, A., Kelliher, M., Johnston, J. A., Ravid, R., Dockery, P., et al. (2005). Activation of Akt/PKB, increased phosphorylation of Akt substrates and loss and altered distribution of Akt and PTEN are features of Alzheimer's disease pathology. J. Neurochem. 93, 105-117. doi: 10.1111/j.1471-4159.2004.02949.x

Groszer, M., Erickson, R., Scripture-Adams, D. D., Lesche, R., Trumpp, A., Zack, J. A., et al. (2001). Negative regulation of neural stem/progenitor cell proliferation by the Pten tumor suppressor gene in vivo. Science 294, 2186-2189. doi: $10.1126 /$ science. 1065518

Hanger, D. P., Hughes, K., Woodgett, J. R., Brion, J. P., and Anderton, B. H. (1992). Glycogen synthase kinase-3 induces Alzheimer's disease-like phosphorylation of tau: generation of paired helical filament epitopes and neuronal localisation of the kinase. Neurosci. Lett. 147, 58-62. doi: 10.1016/0304-3940(92)90774-2 
Hawkins, P. T., Anderson, K. E., Davidson, K., and Stephens, L. R. (2006). Signalling through Class I PI3Ks in mammalian cells. Biochem. Soc. Trans. 34, 647-662. doi: 10.1042/BST0340647

Haws, M. E., Jaramillo, T. C., Espinosa-Becerra, F., Widman, A., Stuber, G. D., Sparta, D. R., et al. (2014). PTEN knockdown alters dendritic spine/protrusion morphology, not density. J. Comp. Neurol. 522, 1171-1190. doi: $10.1002 /$ cne. 23488

Hayashi, K., Ishikawa, R., Ye, L. H., He, X. L., Takata, K., Kohama, K., et al. (1996). Modulatory role of drebrin on the cytoskeleton within dendritic spines in the rat cerebral cortex. J. Neurosci. 16, 7161-7170.

Hedskog, L., Pinho, C. M., Filadi, R., Ronnback, A., Hertwig, L., Wiehager, B., et al. (2013). Modulation of the endoplasmic reticulum-mitochondria interface in Alzheimer's disease and related models. Proc. Natl. Acad. Sci. U.S.A. 110, 7916-7921. doi: 10.1073/pnas.1300677110

Henle, S. J., Carlstrom, L. P., Cheever, T. R., and Henley, J. R. (2013). Differential role of PTEN phosphatase in chemotactic growth cone guidance. J. Biol. Chem. 288, 20837-20842. doi: 10.1074/jbc.C113.487066

Henle, S. J., Wang, G., Liang, E., Wu, M., Poo, M.-M., and Henley, J. R. (2011). Asymmetric PI(3,4,5)P3 and Akt signaling mediates chemotaxis of axonal growth cones. J. Neurosci. 31, 7016-7027. doi: 10.1523/JNEUROSCI.021611.2011

Hobert, J. A., Embacher, R., Mester, J. L., Frazier, T. W. 2nd., and Eng, C. (2014). Biochemical screening and PTEN mutation analysis in individuals with autism spectrum disorders and macrocephaly. Eur. J. Hum. Genet. 22, 273-276. doi: 10.1038/ejhg.2013.114

Hodakoski, C., Hopkins, B. D., Barrows, D., Mense, S. M., Keniry, M., Anderson, K. E., et al. (2014). Regulation of PTEN inhibition by the pleckstrin homology domain of P-REX2 during insulin signaling and glucose homeostasis. Proc. Natl. Acad. Sci. U.S.A. 111, 155-160. doi: 10.1073/pnas.1213773111

Hopkins, B. D., Fine, B., Steinbach, N., Dendy, M., Rapp, Z., Shaw, J., et al. (2013). A secreted PTEN phosphatase that enters cells to alter signaling and survival. Science 341, 399-402. doi: 10.1126/science.1234907

Howitt, J., Lackovic, J., Low, L.-H., Naguib, A., Macintyre, A., Goh, C.-P., et al. (2012). Ndfip1 regulates nuclear Pten import in vivo to promote neuronal survival following cerebral ischemia. J. Cell Biol. 196, 29-36. doi: 10.1083/jcb.201105009

Huang, J., Yan, J., Zhang, J., Zhu, S., Wang, Y., Shi, T., et al. (2012). SUMO1 modification of PTEN regulates tumorigenesis by controlling its association with the plasma membrane. Nat. Commun. 3, 911. doi: 10.1038/ncomms1919.

Hur, E.-M., and Zhou, F.-Q. (2010). GSK3 signalling in neural development. Nat. Rev. Neurosci. 11, 539-551. doi: 10.1038/nrn2870

Inoue, K., Rispoli, J., Yang, L., Macleod, D., Beal, M. F., Klann, E., et al. (2013). Coordinate regulation of mature dopaminergic axon morphology by macroautophagy and the PTEN signaling pathway. PLoS Genet. 9:e1003845. doi: 10.1371/journal.pgen.1003845

Jurado, S., Benoist, M., Lario, A., Knafo, S., Petrok, C. N., and Esteban, J. A. (2010). PTEN is recruited to the postsynaptic terminal for NMDA receptordependent long-term depression. EMBO J. 29, 2827-2840. doi: 10.1038/emboj. 2010.160

Kakumoto, T., and Nakata, T. (2013). Optogenetic control of PIP3: PIP3 is sufficient to induce the actin-based active part of growth cones and is regulated via endocytosis. PloS ONE 8:e70861. doi: 10.1371/journal.pone.0070861

Karunarathne, W. K. A., Giri, L., Patel, A. K., Venkatesh, K. V., and Gautam, N. (2013). Optical control demonstrates switch-like PIP3 dynamics underlying the initiation of immune cell migration. Proc. Natl. Acad. Sci. U.S.A. 110, E15751583. doi: $10.1073 /$ pnas. 1220755110

Kavela, S., Shinde, S. R., Ratheesh, R., Viswakalyan, K., Bashyam, M. D., Gowrishankar, S., et al. (2013). PNUTS functions as a proto-oncogene by sequestering PTEN. Cancer Res. 73, 205-214. doi: 10.1158/0008-5472.CAN12-1394

Kerr, F., Rickle, A., Nayeem, N., Brandner, S., Cowburn, R. F., and Lovestone, S. (2006). PTEN, a negative regulator of PI3 kinase signalling, alters tau phosphorylation in cells by mechanisms independent of GSK-3. FEBS Lett. 580, 3121-3128. doi: 10.1016/j.febslet.2006.04.064

Ketschek, A., and Gallo, G. (2010). Nerve growth factor induces axonal filopodia through localized microdomains of phosphoinositide 3-kinase activity that drive the formation of cytoskeletal precursors to filopodia. J. Neurosci. 30, 12185-12197. doi: 10.1523/JNEUROSCI.1740-10.2010
Kim, J.-I., Lee, H.-R., Sim, S., Baek, J., Yu, N.-K., Choi, J.-H., et al. (2011a). PI3K $\gamma$ is required for NMDA receptor-dependent long-term depression and behavioral flexibility. Nat. Neurosci. 14, 1447-1454. doi: 10.1038/nn.2937

Kim, J.-S., Xu, X., Li, H., Solomon, D., Lane, W. S., Jin, T., et al. (2011b) Mechanistic analysis of a DNA damage-induced, PTEN-dependent size checkpoint in human cells. Mol. Cell. Biol. 31, 2756-2771. doi: 10.1128/MCB. 01323-10

Kirby, J., Ning, K., Ferraiuolo, L., Heath, P. R., Ismail, A., Kuo, S.-W., et al. (2011). Phosphatase and tensin homologue/protein kinase B pathway linked to motor neuron survival in human superoxide dismutase 1-related amyotrophic lateral sclerosis. Brain 134, 506-517. doi: 10.1093/brain/awq345

Klein, S., Sharifi-Hannauer, P., and Martinez-Agosto, J. A. (2013). Macrocephaly as a clinical indicator of genetic subtypes in autism. Autism Res. 6, 51-56. doi: 10.1002/aur.1266

Krause, M., Leslie, J. D., Stewart, M., Lafuente, E. M., Valderrama, F., Jagannathan, R., et al. (2004). Lamellipodin, an Ena/VASP ligand, is implicated in the regulation of lamellipodial dynamics. Dev. Cell 7, 571-583. doi: 10.1016/j.devcel.2004.07.024

Kreis, P., Hendricusdottir, R., Kay, L., Papageorgiou, I. E., van Diepen, M., Mack, T., et al. (2013). Phosphorylation of the actin binding protein Drebrin at S647 is regulated by neuronal activity and PTEN. PLOS ONE 8:e71957. doi: 10.1371/journal.pone.0071957

Kreis, P., van Diepen, M. T., and Eickholt, B. J. (2010). Regulation of PTEN in neurons by myosin-based transport mechanisms. Adv. Enzyme Regul. 50, 119-124. doi: 10.1016/j.advenzreg.2009.10.014

Krugmann, S., Anderson, K. E., Ridley, S. H., Risso, N., McGregor, A., Coadwell, J., et al. (2002). Identification of ARAP3, a novel PI3K effector regulating both Arf and Rho GTPases, by selective capture on phosphoinositide affinity matrices. Mol. Cell 9, 95-108. doi: 10.1016/S1097-2765(02)00434-3

Kwak, Y.-D., Ma, T., Diao, S., Zhang, X., Chen, Y., Hsu, J., et al. (2010). NO signaling and S-nitrosylation regulate PTEN inhibition in neurodegeneration. Mol. Neurodegener. 5, 49. doi: 10.1186/1750-1326-5-49

Kwon, C.-H., Luikart, B. W., Powell, C. M., Zhou, J., Matheny, S. A., Zhang, W., et al. (2006). Pten regulates neuronal arborization and social interaction in mice. Neuron 50, 377-388. doi: 10.1016/j.neuron.2006.03.023

Kwon, C. H., Zhu, X., Zhang, J., Knoop, L. L., Tharp, R., Smeyne, R. J., et al. (2001). Pten regulates neuronal soma size: a mouse model of Lhermitte-Duclos disease. Nat. Genet. 29, 404-411. doi: 10.1038/ng781

Lachlan, K. L., Lucassen, A. M., Bunyan, D., and Temple, I. K. (2007). Cowden syndrome and Bannayan Riley Ruvalcaba syndrome represent one condition with variable expression and age-related penetrance: results of a clinical study of PTEN mutation carriers. J. Med. Genet. 44, 579-585. doi: 10.1136/jmg.2007.049981

Lachyankar, M. B., Sultana, N., Schonhoff, C. M., Mitra, P., Poluha, W., Lambert, S., et al. (2000). A role for nuclear PTEN in neuronal differentiation. J. Neurosci. 20, 1404-1413.

Lee, J. O., Yang, H., Georgescu, M. M., Di Cristofano, A., Maehama, T., Shi, Y., et al. (1999). Crystal structure of the PTEN tumor suppressor: implications for its phosphoinositide phosphatase activity and membrane association. Cell 99, 323-334. doi: 10.1016/S0092-8674(00)81663-3

Leslie, N. R., Batty, I. H., Maccario, H., Davidson, L., and Downes, C. P. (2008). Understanding PTEN regulation: PIP2, polarity and protein stability. Oncogene 27, 5464-5476. doi: 10.1038/onc.2008.243

Li, Z., Dong, X., Dong, X., Wang, Z., Liu, W., Deng, N., et al. (2005). Regulation of PTEN by Rho small GTPases. Nat. Cell Biol. 7, 399-404. doi: 10.1038/ncb1236

Lian, Z., and Di Cristofano, A. (2005). Class reunion: PTEN joins the nuclear crew. Oncogene 24, 7394-7400. doi: 10.1038/sj.onc.1209089

Lima-Fernandes, E., Enslen, H., Camand, E., Kotelevets, L., Boularan, C., Achour, L., et al. (2011). Distinct functional outputs of PTEN signalling are controlled by dynamic association with beta-arrestins. EMBO J. 30, 2557-2568. doi: 10.1038/emboj.2011.178

Lindhurst, M. J., Sapp, J. C., Teer, J. K., Johnston, J. J., Finn, E. M., Peters, K., et al. (2011). A mosaic activating mutation in AKT1 associated with the Proteus syndrome. N. Engl. J. Med. 365, 611-619. doi: 10.1056/NEJMoa1104017

Lindsay, Y., McCoull, D., Davidson, L., Leslie, N. R., Fairservice, A., Gray, A., et al. (2006). Localization of agonist-sensitive PtdIns $(3,4,5) P 3$ reveals a nuclear pool that is insensitive to PTEN expression. J. Cell Sci. 119, 5160-5168. doi: $10.1242 /$ jcs. 000133 
Liu, K., Lu, Y., Lee, J. K., Samara, R., Willenberg, R., Sears-Kraxberger, I., et al. (2010). PTEN deletion enhances the regenerative ability of adult corticospinal neurons. Nat. Neurosci. 13, 1075-1081. doi: 10.1038/nn.2603

Luikart, B. W., Schnell, E., Washburn, E. K., Bensen, A. L., Tovar, K. R., and Westbrook, G. L. (2011). Pten knockdown in vivo increases excitatory drive onto dentate granule cells. J. Neurosci. 31, 4345-4354. doi: 10.1523/JNEUROSCI.0061-11.2011

Lumb, C. N., and Sansom, M. S. P. (2013). Defining the membrane-associated state of the PTEN tumor suppressor protein. Biophys. J. 104, 613-621. doi: 10.1016/j.bpj.2012.12.002

Luo, X., and Park, K. K. (2012). Neuron-intrinsic inhibitors of axon regeneration: PTEN and SOCS3. Int. Rev. Neurobiol. 105, 141-173. doi: 10.1016/B978-0-12398309-1.00008-1

Maccario, H., Perera, N. M., Gray, A., Downes, C. P., and Leslie, N. R. (2010). Ubiquitination of PTEN (phosphatase and tensin homolog) inhibits phosphatase activity and is enhanced by membrane targeting and hyperosmotic stress. J. Biol. Chem. 285, 12620-12628. doi: 10.1074/jbc.M109.072280

Malaney, P., Pathak, R. R., Xue, B., Uversky, V. N., and Dave, V. (2013). Intrinsic disorder in PTEN and its interactome confers structural plasticity and functional versatility. Sci. Rep. 3:2035. doi: 10.1038/srep02035

Mao, L., Jia, J., Zhou, X., Xiao, Y., Wang, Y., Mao, X., et al. (2013). Delayed administration of a PTEN inhibitor BPV improves functional recovery after experimental stroke. Neuroscience 231, 272-281. doi: 10.1016/j.neuroscience.2012. 11.050

McBride, K. L., Varga, E. A., Pastore, M. T., Prior, T. W., Manickam, K., Atkin, J. F., et al. (2010). Confirmation study of PTEN mutations among individuals with autism or developmental delays/mental retardation and macrocephaly. Autism Res. 3, 137-141. doi: 10.1002/aur.132

Mester, J., and Eng, C. (2013). When overgrowth bumps into cancer: the PTENopathies. Am. J. Med. Genet. C Semin. Med. Genet. 163C, 114-121. doi: 10.1002/j.1552-4876.2013.31364.x

Mester, J. L., Tilot, A. K., Rybicki, L. A., Frazier, T. W. 2nd., and Eng, C. (2011). Analysis of prevalence and degree of macrocephaly in patients with germline PTEN mutations and of brain weight in Pten knock-in murine model. Eur. J. Hum. Genet. 19, 763-768. doi: 10.1038/ejhg.2011.20

Molina, J. R., Agarwal, N. K., Morales, F. C., Hayashi, Y., Aldape, K. D., Cote, G., et al. (2012). PTEN, NHERF1 and PHLPP form a tumor suppressor network that is disabled in glioblastoma. Oncogene 31, 1264-1274. doi: 10.1038/onc. 2011.324

Moncalero, V. L., Costanzo, R. V., Perandones, C., and Radrizzani, M. (2011). Different conformations of phosphatase and tensin homolog, deleted on chromosome 10 (PTEN) protein within the nucleus and cytoplasm of neurons. PloS ONE 6:e18857. doi: 10.1371/journal.pone.0018857

Mund, T., and Pelham, H. R. B. (2010). Regulation of PTEN/Akt and MAP kinase signaling pathways by the ubiquitin ligase activators Ndfip1 and Ndfip2. Proc. Natl. Acad. Sci. U.S.A. 107, 11429-11434. doi: 10.1073/pnas.0911714107

Myers, M. P., Pass, I., Batty, I. H., Van der Kaay, J., Stolarov, J. P., Hemmings, B. A., et al. (1998). The lipid phosphatase activity of PTEN is critical for its tumor supressor function. Proc. Natl. Acad. Sci. U.S.A. 95, 13513-13518. doi: 10.1073/pnas.95.23.13513

Nguyen, H. N., Afkari, Y., Senoo, H., Sesaki, H., Devreotes, P. N., and Iijima, M. (2013). Mechanism of human PTEN localization revealed by heterologous expression in Dictyostelium. Oncogene. doi: 10.1038/onc.2013.507. [Epub ahead of print].

Ning, K., Drepper, C., Valori, C. F., Ahsan, M., Wyles, M., Higginbottom, A., et al. (2010). PTEN depletion rescues axonal growth defect and improves survival in SMN-deficient motor neurons. Hum. Mol. Genet. 19, 3159-3168. doi: $10.1093 / \mathrm{hmg} / \mathrm{ddq} 226$

Odriozola, L., Singh, G., Hoang, T., and Chan, A. M. (2007). Regulation of PTEN activity by its carboxyl-terminal autoinhibitory domain. J. Biol. Chem. 282, 23306-23315. doi: 10.1074/jbc.M611240200

Oinuma, I., Ito, Y., Katoh, H., and Negishi, M. (2010). Semaphorin 4D/PlexinB1 stimulates PTEN activity through R-Ras GTPase-activating protein activity, inducing growth cone collapse in hippocampal neurons. J. Biol. Chem. 285, 28200-28209. doi: 10.1074/jbc.M110.147546

Orloff, M. S., He, X., Peterson, C., Chen, F., Chen, J.-L., Mester, J. L., et al. (2013). Germline PIK3CA and AKT1 mutations in Cowden and Cowden-like syndromes. Am. J. Hum. Genet. 92, 76-80. doi: 10.1016/j.ajhg.2012.10.021
Orrico, A., Galli, L., Buoni, S., Orsi, A., Vonella, G., and Sorrentino, V. (2009). Novel PTEN mutations in neurodevelopmental disorders and macrocephaly. Clin. Genet.75, 195-198. doi: 10.1111/j.1399-0004.2008.01074.x

Papakonstanti, E. A., Ridley, A. J., and Vanhaesebroeck, B. (2007). The p110delta isoform of PI 3-kinase negatively controls RhoA and PTEN. EMBO J. 26, 3050-3061. doi: 10.1038/sj.emboj.7601763

Park, K. K., Liu, K., Hu, Y., Smith, P. D., Wang, C., Cai, B., et al. (2008). Promoting axon regeneration in the adult CNS by modulation of the PTEN/mTOR pathway. Science 322, 963-966. doi: 10.1126/science.1161566

Perdigoto, A. L., Chaudhry, N., Barnes, G. N., Filbin, M. T., and Carter, B. D. (2011). A novel role for PTEN in the inhibition of neurite outgrowth by myelinassociated glycoprotein in cortical neurons. Mol. Cell. Neurosci. 46, 235-244. doi: 10.1016/j.mcn.2010.09.006

Pilarski, R., Burt, R., Kohlman, W., Pho, L., Shannon, K. M., and Swisher, E. (2013). Cowden syndrome and the PTEN hamartoma tumor syndrome: systematic review and revised diagnostic criteria. J. Natl. Cancer Inst. 105, 1607-1616. doi: 10.1093/jnci/djt277

Planchon, S. M., Waite, K. A., and Eng, C. (2008). The nuclear affairs of PTEN. J. Cell Sci. 121, 249-253. doi: 10.1242/jcs.022459

Putz, U., Howitt, J., Doan, A., Goh, C.-P., Low, L.-H., Silke, J., et al. (2012). The tumor suppressor PTEN is exported in exosomes and has phosphatase activity in recipient cells. Sci. Signal. 5:ra70. doi: 10.1126/scisignal.2003084

Raftopoulou, M., Etienne-Manneville, S., Self, A., Nicholls, S., and Hall, A. (2004). Regulation of cell migration by the $\mathrm{C} 2$ domain of the tumor suppressor PTEN. Science 303, 1179-1181. doi: 10.1126/science.1092089

Rahdar, M., Inoue, T., Meyer, T., Zhang, J., Vazquez, F., and Devreotes, P. N. (2009). A phosphorylation-dependent intramolecular interaction regulates the membrane association and activity of the tumor suppressor PTEN. Proc. Natl. Acad. Sci. U.S.A. 106, 480-485. doi: 10.1073/pnas.0811212106

Raposo, G., and Stoorvogel, W. (2013). Extracellular vesicles: exosomes, microvesicles, and friends. J. Cell Biol. 200, 373-383. doi: 10.1083/jcb.201211138

Redfern, R. E., Daou, M. C., Li, L., Munson, M., Gericke, A., and Ross, A. H. (2010). A mutant form of PTEN linked to autism. Protein Sci. 19, 1948-1956. doi: $10.1002 /$ pro. 483

Redfern, R. E., Redfern, D., Furgason, M. L., Munson, M., Ross, A. H., and Gericke, A. (2008). PTEN phosphatase selectively binds phosphoinositides and undergoes structural changes. Biochemistry (Mosc.) 47, 2162-2171. doi: 10.1021/bi702114w

Ries, V., Henchcliffe, C., Kareva, T., Rzhetskaya, M., Bland, R., During, M. J., et al. (2006). Oncoprotein Akt/PKB induces trophic effects in murine models of Parkinson's disease. Proc. Natl. Acad. Sci. U.S.A. 103, 18757-18762. doi: 10.1073/pnas.0606401103

Rodríguez-Escudero, I., Oliver, M. D., Andrés-Pons, A., Molina, M., Cid, V. J., and Pulido, R. (2011). A comprehensive functional analysis of PTEN mutations: implications in tumor- and autism-related syndromes. Hum. Mol. Genet. 20, 4132-4142. doi: $10.1093 / \mathrm{hmg} / \mathrm{ddr} 337$

Ross, A. H., and Gericke, A. (2009). Phosphorylation keeps PTEN phosphatase closed for business. Proc. Natl. Acad. Sci. U.S.A. 106, 1297-1298. doi: $10.1073 /$ pnas. 0812473106

Sanchez, T., Thangada, S., Wu, M. T., Kontos, C. D., Wu, D., Wu, H., et al. (2005), PTEN as an effector in the signaling of antimigratory $\mathrm{G}$ protein-coupled receptor. Proc. Natl. Acad. Sci. U.S.A. 102, 4312-4317. doi: 10.1073/pnas.0409784102

Shen, W. H., Balajee, A. S., Wang, J., Wu, H., Eng, C., Pandolfi, P. P., et al. (2007). Essential role for nuclear PTEN in maintaining chromosomal integrity. Cell 128, 157-170. doi: 10.1016/j.cell.2006.11.042

Shenoy, S., Shekhar, P., Heinrich, F., Daou, M. C., Gericke, A., Ross, A. H., et al. (2012). Membrane association of the PTEN tumor suppressor: molecular details of the protein-membrane complex from SPR binding studies and neutron reflection. PLoS ONE 7:e32591. doi: 10.1371/journal.pone.0032591

Shewan, A., Eastburn, D. J., and Mostov, K. (2011). Phosphoinositides in cell architecture. Cold Spring Harb. Perspect. Biol. 3:a004796. doi: 10.1101/cshperspect.a004796

Shi, Y., Paluch, B. E., Wang, X., and Jiang, X. (2012). PTEN at a glance. J. Cell Sci. 125, 4687-4692. doi: 10.1242/jcs.093765

Song, M. S., Carracedo, A., Salmena, L., Song, S. J., Egia, A., Malumbres, M., et al. (2011). Nuclear PTEN regulates the APC-CDH1 tumor-suppressive complex in a phosphatase-independent manner. Cell 144, 187-199. doi: 10.1016/j.cell.2010.12.020 
Song, M. S., Salmena, L., Carracedo, A., Egia, A., Lo-Coco, F., Teruya-Feldstein, J., et al. (2008). The deubiquitinylation and localization of PTEN are regulated by a HAUSP-PML network. Nature 455, 813-817. doi: 10.1038/nature07290

Song, M. S., Salmena, L., and Pandolfi, P. P. (2012). The functions and regulation of the PTEN tumour suppressor. Nat. Rev. Mol. Cell Biol. 13, 283-296. doi: $10.1038 / \mathrm{nrm} 3330$

Sonoda, Y., Mukai, H., Matsuo, K., Takahashi, M., Ono, Y., Maeda, K., et al. (2010). Accumulation of tumor-suppressor PTEN in Alzheimer neurofibrillary tangles. Neurosci. Lett. 471, 20-24. doi: 10.1016/j.neulet.2009.12.078

Sperow, M., Berry, R. B., Bayazitov, I. T., Zhu, G., Baker, S. J., and Zakharenko, S. S. (2012). Phosphatase and tensin homologue (PTEN) regulates synaptic plasticity independently of its effect on neuronal morphology and migration. J. Physiol. 590, 777-792. doi: 10.1113/jphysiol.2011.220236

Spillane, M., Ketschek, A., Jones, S. L., Korobova, F., Marsick, B., Lanier, L., et al. (2011). The actin nucleating Arp2/3 complex contributes to the formation of axonal filopodia and branches through the regulation of actin patch precursors to filopodia. Dev. Neurobiol. 71, 747-758. doi: 10.1002/dneu.20907

Sumitomo, M., Iwase, A., Zheng, R., Navarro, D., Kaminetzky, D., Shen, R., et al. (2004). Synergy in tumor suppression by direct interaction of neutral endopeptidase with PTEN. Cancer Cell 5, 67-78. doi: 10.1016/S1535-6108(03)00331-3

Sun, F., Park, K. K., Belin, S., Wang, D., Lu, T., Chen, G., et al. (2011). Sustained axon regeneration induced by co-deletion of PTEN and SOCS3. Nature 480, 372-375. doi: 10.1038/nature10594

Takeuchi, K., Gertner, M. J., Zhou, J., Parada, L. F., Bennett, M. V. L., and Zukin, R. S. (2013). Dysregulation of synaptic plasticity precedes appearance of morphological defects in a Pten conditional knockout mouse model of autism. Proc. Natl. Acad. Sci. U.S.A. 110, 4738-4743. doi: 10.1073/pnas.1222803110

Tamura, M., Gu, J., Danen, E. H., Takino, T., Miyamoto, S., and Yamada, K. M. (1999). PTEN interactions with focal adhesion kinase and suppression of the extracellular matrix-dependent phosphatidylinositol 3-kinase/Akt cell survival pathway. J. Biol. Chem. 274, 20693-20703. doi: 10.1074/jbc.274.29.20693

Tamura, M., Gu, J., Matsumoto, K., Aota, S., Parsons, R., and Yamada, K. M. (1998). Inhibition of cell migration, spreading, and focal adhesions by tumor suppressor PTEN. Science 280, 1614-1617. doi: 10.1126/science.280.5369.1614

Terrien, E., Chaffotte, A., Lafage, M., Khan, Z., Préhaud, C., Cordier, F., et al. (2012). Interference with the PTEN-MAST2 interaction by a viral protein leads to cellular relocalization of PTEN. Sci. Signal. 5:ra58. doi: 10.1126/scisignal.20 02941

Tibarewal, P., Zilidis, G., Spinelli, L., Schurch, N., Maccario, H., Gray, A., et al. (2012). PTEN protein phosphatase activity correlates with control of gene expression and invasion, a tumor-suppressing phenotype, but not with AKT activity. Sci. Signal. 5, ra18. doi: 10.1126/scisignal.2002138

Trotman, L. C., Wang, X., Alimonti, A., Chen, Z., Teruya-Feldstein, J., Yang, H., et al. (2007). Ubiquitination regulates PTEN nuclear import and tumor suppression. Cell 128, 141-156. doi: 10.1016/j.cell.2006.11.040

Ueda, Y., and Hayashi, Y. (2013). PIP3 regulates spinule formation in dendritic spines during structural long-term potentiation. J. Neurosci. 33, 11040-11047. doi: 10.1523/JNEUROSCI.3122-12.2013

Van Diepen, M. T., and Eickholt, B. J. (2008). Function of PTEN during the formation and maintenance of neuronal circuits in the brain. Dev. Neurosci. 30, 59-64. doi: 10.1159/000109852

Van Diepen, M. T., Parsons, M., Downes, C. P., Leslie, N. R., Hindges, R., and Eickholt, B. J. (2009). MyosinV controls PTEN function and neuronal cell size. Nat. Cell Biol. 11, 1191-1196. doi: 10.1038/ncb1961

Vanhaesebroeck, B., Guillermet-Guibert, J., Graupera, M., and Bilanges, B. (2010). The emerging mechanisms of isoform-specific PI3K signalling. Nat. Rev. Mol. Cell Biol. 11, 329-341. doi: 10.1038/nrm2882

Vanhaesebroeck, B., Stephens, L., and Hawkins, P. (2012). PI3K signalling: the path to discovery and understanding. Nat. Rev. Mol. Cell Biol. 13, 195-203. doi: $10.1038 / \mathrm{nrm} 3290$

Varga, E. A., Pastore, M., Prior, T., Herman, G. E., and McBride, K. L. (2009). The prevalence of PTEN mutations in a clinical pediatric cohort with autism spectrum disorders, developmental delay, and macrocephaly. Genet. Med. 11, 111-117. doi: 10.1097/GIM.0b013e31818fd762

Vazquez, F., and Devreotes, P. (2006). Regulation of PTEN function as a PIP3 gatekeeper through membrane interaction. Cell Cycle 5, 1523-1527. doi: $10.4161 /$ cc.5.14.3005

Vazquez, F., Grossman, S. R., Takahashi, Y., Rokas, M. V., Nakamura, N., and Sellers, W. R. (2001). Phosphorylation of the PTEN tail acts as an inhibitory switch by preventing its recruitment into a protein complex. J. Biol. Chem. 276, 48627-48630. doi: 10.1074/jbc.C100556200

Vazquez, F., Matsuoka, S., Sellers, W. R., Yanagida, T., Ueda, M., and Devreotes, P. N. (2006). Tumor suppressor PTEN acts through dynamic interaction with the plasma membrane. Proc. Natl. Acad. Sci. U.S.A. 103, 3633-3638. doi: 10.1073/pnas.0510570103

Von Stein, W., Ramrath, A., Grimm, A., Muller-Borg, M., and Wodarz, A. (2005). Direct association of Bazooka/PAR-3 with the lipid phosphatase PTEN reveals a link between the PAR/aPKC complex and phosphoinositide signaling. Development 132, 1675-1686. doi: 10.1242/dev.01720

Waite, K., and Eickholt, B. J. (2010). The neurodevelopmental implications of PI3K signaling. Curr. Top. Microbiol. Immunol. 346, 245-265. doi: 10.1007/82_2010_82

Walker, C. L., Walker, M. J., Liu, N.-K., Risberg, E. C., Gao, X., Chen, J., et al. (2012). Systemic bisperoxovanadium activates Akt/mTOR, reduces autophagy, and enhances recovery following cervical spinal cord injury. PloS ONE 7:e30012. doi: 10.1371/journal.pone.0030012

Walker, S. M., Leslie, N. R., Perera, N. M., Batty, I. H., and Downes, C. P. (2004). The tumour-suppressor function of PTEN requires an Nterminal lipid-binding motif. Biochem. J. 379, 301-307. doi: 10.1042/ BJ20031839

Wei, W., Wang, X., and Kusiak, J. W. (2002). Signaling events in amyloid betapeptide-induced neuronal death and insulin-like growth factor I protection. J. Biol. Chem. 277, 17649-17656. doi: 10.1074/jbc.M111704200

Welch, H. C. E., Coadwell, W. J., Ellson, C. D., Ferguson, G. J., Andrews, S. R., Erdjument-Bromage, H., et al. (2002). P-Rex1, a PtdIns(3,4,5)P3- and Gbetagamma-regulated guanine-nucleotide exchange factor for Rac. Cell 108, 809-821. doi: 10.1016/S0092-8674(02)00663-3

Won, H., Mah, W., and Kim, E. (2013). Autism spectrum disorder causes, mechanisms, and treatments: focus on neuronal synapses. Front. Mol. Neurosci. 6:19. doi: $10.3389 /$ fnmol.2013.00019

Worth, D. C., Daly, C. N., Geraldo, S., Oozeer, F., and Gordon-Weeks, P. R. (2013). Drebrin contains a cryptic F-actin-bundling activity regulated by Cdk5 phosphorylation. J. Cell Biol. 202, 793-806. doi: 10.1083/jcb.201303005

Wu, H., Feng, W., Chen, J., Chan, L. N., Huang, S., and Zhang, M. (2007). PDZ domains of Par-3 as potential phosphoinositide signaling integrators. Mol. Cell 28, 886-898. doi: 10.1016/j.molcel.2007.10.028

Wu, X., Hepner, K., Castelino-Prabhu, S., Do, D., Kaye, M. B., Yuan, X. J., et al. (2000). Evidence for regulation of the PTEN tumor suppressor by a membranelocalized multi-PDZ domain containing scaffold protein MAGI-2. Proc. Natl. Acad. Sci. U.S.A. 97, 4233-4238. doi: 10.1073/pnas.97.8.4233

Yin, H. L., and Janmey, P. A. (2003). Phosphoinositide regulation of the actin cytoskeleton. Annu. Rev. Physiol. 65, 761-789. doi: 10.1146/annurev.physiol.65.092101.142517

Yoshinaga, S., Ohkubo, T., Sasaki, S., Nuriya, M., Ogawa, Y., Yasui, M., et al. (2012). A phosphatidylinositol lipids system, lamellipodin, and Ena/VASP regulate dynamic morphology of multipolar migrating cells in the developing cerebral cortex. J. Neurosci. 32, 11643-11656. doi: 10.1523/JNEUROSCI.0738-12.2012

Zhang, S., Taghibiglou, C., Girling, K., Dong, Z., Lin, S.-Z., Lee, W., et al. (2013). Critical role of increased PTEN nuclear translocation in excitotoxic and ischemic neuronal injuries. J. Neurosci. 33, 7997-8008. doi: 10.1523/JNEUROSCI.5661-12.2013

Zhang, X., Li, F., Bulloj, A., Zhang, Y.-W., Tong, G., Zhang, Z., et al. (2006). Tumor-suppressor PTEN affects tau phosphorylation, aggregation, and binding to microtubules. FASEB J. 20, 1272-1274. doi: 10.1096/fj.06-5721fje

Zhang, X. C., Piccini, A., Myers, M. P., Van Aelst, L., and Tonks, N. K. (2012a). Functional analysis of the protein phosphatase activity of PTEN. Biochem. J. 444, 457-464. doi: 10.1042/BJ20120098

Zhang, Y., Granholm, A.-C., Huh, K., Shan, L., Diaz-Ruiz, O., Malik, N., et al. (2012b). PTEN deletion enhances survival, neurite outgrowth and function of dopamine neuron grafts to MitoPark mice. Brain 135, 2736-2749. doi: 10.1093/brain/aws196

Zhou, J., Blundell, J., Ogawa, S., Kwon, C.-H., Zhang, W., Sinton, C., et al. (2009). Pharmacological inhibition of mTORC1 suppresses anatomical, cellular, and behavioral abnormalities in neural-specific Pten knock-out mice. J. Neurosci. 29, 1773-1783. doi: 10.1523/JNEUROSCI.568508.2009

Zhou, J., and Parada, L. F. (2012). PTEN signaling in autism spectrum disorders. Curr. Opin. Neurobiol. 22, 873-879. doi: 10.1016/j.conb.2012.05.004 
Zhu, Y., Hoell, P., Ahlemeyer, B., and Krieglstein, J. (2006). PTEN: a crucial mediator of mitochondria-dependent apoptosis. Apoptosis 11, 197-207. doi: 10.1007/s10495-006-3714-5

Zhu, Y., Hoell, P., Ahlemeyer, B., Sure, U., Bertalanffy, H., and Krieglstein, J. (2007). Implication of PTEN in production of reactive oxygen species and neuronal death in in vitro models of stroke and Parkinson's disease. Neurochem. Int. 50, 507-516. doi: 10.1016/j.neuint.2006.10.010

Zu, L., Zheng, X., Wang, B., Parajuli, N., Steenbergen, C., Becker, L. C., et al. (2011). Ischemic preconditioning attenuates mitochondrial localization of PTEN induced by ischemia-reperfusion. Am. J. Physiol. Heart Circ. Physiol. 300, H2177-H2186. doi: 10.1152/ajpheart.01138.2010

Zukor, K., Belin, S., Wang, C., Keelan, N., Wang, X., and He, Z. (2013). Short hairpin RNA against PTEN enhances regenerative growth of corticospinal tract axons after spinal cord injury. J. Neurosci. 33, 15350-15361. doi: 10.1523/JNEUROSCI.2510-13.2013
Conflict of Interest Statement: The authors declare that the research was conducted in the absence of any commercial or financial relationships that could be construed as a potential conflict of interest.

Received: 30 January 2014; accepted: 12 March 2014; published online: 01 April 2014 Citation: Kreis P, Leondaritis G, Lieberam I and Eickholt BJ (2014) Subcellular targeting and dynamic regulation of PTEN: implications for neuronal cells and neurological disorders. Front. Mol. Neurosci. 7:23. doi: 10.3389/fnmol.2014.00023

This article was submitted to the journal Frontiers in Molecular Neuroscience.

Copyright (c) 2014 Kreis, Leondaritis, Lieberam and Eickholt. This is an open-access article distributed under the terms of the Creative Commons Attribution License (CC BY). The use, distribution or reproduction in other forums is permitted, provided the original author(s) or licensor are credited and that the original publication in this journal is cited, in accordance with accepted academic practice. No use, distribution or reproduction is permitted which does not comply with these terms. 